Article

\title{
Inter-University Sustainability Benchmarking for Canadian Higher Education Institutions: Water, Energy, and Carbon Flows for Technical-Level Decision-Making
}

\author{
Abdulaziz Alghamdi ${ }^{1, *}$, Husnain Haider ${ }^{2}$, Kasun Hewage ${ }^{1}$ and Rehan Sadiq ${ }^{1}$ \\ 1 School of Engineering, University of British Columbia (Okanagan), 3333 University Way, Kelowna, \\ BC V1V 1V7, Canada; kasun.hewage@ubc.ca (K.H.); rehan.sadiq@ubc.ca (R.S.) \\ 2 Civil Engineering Department, College of Engineering, Qassim University, Buraydah, \\ Qassim 52571, Saudi Arabia; husnain@qec.edu.sa \\ * Correspondence: aziz.ghamdi@alumni.ubc.ca; Tel.: +1-250-899-4073
}

Received: 16 April 2019; Accepted: 2 May 2019; Published: 6 May 2019

\begin{abstract}
The education sector is one of the major contributors to the total greenhouse gas (GHG) emissions in Canada, i.e., 16\% of total emissions among 11 sectors. Canadian higher education institutions (HEIs) consume around $60 \%$ of the total energy fed to the educational sector. Existing tools holistically cover a wide array of functions to assess the sustainability of HEIs. The infrastructure (engineered) systems are the pivotal units responsible for the majority of energy and water consumption and may have been built, retrofitted, or replaced at different times using different materials and technologies. Consequently, infrastructures have varying efficiency, designs, building envelopes, and environmental impacts. For technical-level decision making for improving the engineered systems, HEIs need to be benchmarked on the basis of their water, energy, and carbon flows. A methodology is developed for sustainability assessment of 34 Canadian HEIs that are classified into small, medium, and large sizes based on their number of full-time equivalent students (FTE). Energy, water consumption, number of students, and floor area is measured in different units and are, thus, normalized. The study revealed that the energy source was the primary factor affecting the sustainability performance of an institution. The analysis also revealed that small-sized institutions outperformed medium-to-large-sized institutions.
\end{abstract}

Keywords: higher education institutions; sustainability assessment; benchmarking; energy flow; carbon flow; sustainable development

\section{Introduction}

Higher educational institutions (HEIs), such as universities and colleges, are mandated to educate citizens, engage communities, lead innovation, and serve as hubs for science and research [1]. Owing to the specific role of universities in fostering talent and educating future generations, it can be argued that universities should have higher positive impact on a community than any other public sector [2-4]. Universities also have large socio-economic impacts on their communities. For instance, 96 Canadian HEIs with a cumulative budget of $\$ 35$ billion/year employ around 250,000 people [5]. This amount is approximately $2.79 \%$ of the nation's gross domestic production [6]. Appreciating their worth, HEIs have been promoting and implementing sustainable development (SD) principles in their growth plans over the past few decades [7].

In the 21st century, SD has been recognized as an important concept in the perspective of socio-economic and environmental entangled policies [8]. HEIs are assessing their overall sustainability 
in the wider context by situating the concepts of sustainability in all their functions, including academics (e.g., curriculum and research activities), engagement (e.g., employee orientation and community participation), planning and administration (e.g., participatory governance, diversity, and equity coordination), and operations (e.g., climate, buildings, energy, transportation, and water) [9]. For example, Bauer et al. [10] applied an empirical approach to improving the sustainability governance at universities in Germany which covers politics, profession, organization, knowledge, and visibility. Universities are complex physical infrastructure systems housing roads, water, and wastewater facilities, and different types of buildings that vary in scope, operation, characteristics, and area. Universities may be regarded as a small city [11]. The significance or magnitude of infrastructures in Canadian HEIs has yet to be adequately realized.

The National Science Foundation defined an engineered system as "a combination of components that work in synergy to collectively perform a useful function," such as manufacturing processes, technologies to improve quality of service, or infrastructure systems [12]. In HEIs, the operation of engineered (infrastructure) systems and other activities (i.e., educational services, recreation and sports, and other extra-curricular activities) utilize immense natural resources to meet water and energy requirements and, consequently, produce carbon emissions. The existing approaches discussed in the following section aggregate the performance of all the functions to rank HEIs based on their overall sustainability. The final outcomes mask the actual facts about the utilization of natural resources and environmental impacts in an HEI. Hence, a sustainability assessment of these engineered systems in terms of water, energy, and carbon (WEC) flows is essential for technical-level decision making about improving their performance on a continuous and long-term basis (e.g., greener energy source, efficient plumbing fixtures and lighting systems, wastewater and waste to energy recycling, and building retrofits).

Globally, HEIs have been identified as one of the major sources of greenhouse gas (GHG) emissions in an urban setting. A study in the UK revealed that energy consumption increased by $2.7 \%$ and the related $\mathrm{CO}_{2}$ emissions rose by $4.3 \%$ between 2005 and 2006. Overall, GHG emissions generated through HEIs in the UK soared from 1.78 to $2.05 \mathrm{tCO}_{2} \mathrm{e}$ (metric tons of carbon equivalent) during the period from 1990 to 2005 [13]. Similarly, in China, universities are the largest public sector contributing to the total GHG emissions by consuming $40 \%$ of the energy devoted to the public sector [14]. Emissions per student at the Norwegian University of Technology and Science were significantly higher than the national average emission reported per citizen. Consequently, HEIs have been investing more in terms of investments to reduce their carbon emissions [15].

Educational services have been subgrouped under Canada's largest activity category as the commercial and institutional (C\&I) sector. Emissions from the Canadian C\&I sector are predicted to increase by $23 \%$ by 2020 from the 2011 reported values [16]. The C\&I sector consumes $10 \%$ of the total energy and emits $9 \%$ of the nation's GHG production as of 2013 [17]. It is estimated that educational services have consumed $16 \%$ of the total energy supplied to the C\&I sector at a staggering value of 134.7 PJ (Petajoule) $\sim 1.34 \times 10^{8} \mathrm{GJ}$ (Gigajoules) in 2009. If this trend continues, these services are likely to become the country's largest emission producing subgroup in the C\&I category. Furthermore, HEIs alone represent $60 \%$ of the total energy consumption in the educational sector (i.e., both primary and higher education), which is equivalent to approximately 430,000 households in Canada [18,19]. Canadian HEIs primarily rely on the national electricity grid that is often produced by fossil fuels and emits high GHG emissions. As HEIs consume water and energy (i.e., input flows) and produce GHG emissions (i.e., output flows), the term WEC flows is used for convenience.

The main objectives of this study were are to: (i) comprehensively review the current state of sustainability in HEIs including international declarations, reporting systems, and size-based classification, (ii) establish sized-based classification criteria for universities, (iii) develop a WEC flow weighting criteria and assessment methodology to be used for sustainability assessment of engineered systems in HEIs, and (iv) benchmark the Canadian HEIs based on their WEC flows for 
effective technical-level decision making for continuous performance improvement and to achieve long-term sustainability.

The present study encompasses WEC flows for 34 HEIs where 617,325 full-time equivalent (FTE) students used 12.7 million $\mathrm{m}^{2}$ of building area. The combined energy usage in these HEIs was approximately $20 \mathrm{GJ}$. Statistical analysis was performed to fit a relationship between the response variable (GHG emissions) and other parameters, such as climate, energy, water, area, and the number of occupants (FTEs). Finally, a mathematical model was developed to rank the universities based on their WEC flows. The findings provided a platform to identify the underperforming HEIs and compare them with the excelling HEIs to highlight the most important factors affecting the ranking score.

\section{Background}

\subsection{Sustainable Development in HEIs}

The idea of sustainability in HEIs was introduced in the Stockholm declaration held in 1972 [20]. The historical background of declarations on the sustainability of HEIs developed by different organizations around the globe is given in Appendix A. For several years, the emphasis of the declarations was on introducing, integrating, and implementing the concepts of sustainability in HEI curricula development, enhancing teaching techniques, securing research funding [21,22], promoting awareness in the general public [23], and developing regional and international networks to support the concept of sustainability in HEIs [21-24]. Until the start of the 21st century, although the declarations prompted HEIs to comply with the stated objectives, the declarations were vague and did not measure the sustainability performance of HEIs at an operational level [25].

Velazquez et al. [26] formally included the impact of resource utilization in the sustainability of a university campus. They defined a sustainable university as "a whole or as a part, that addresses, involves and promotes, on a global level, the minimization of negative environmental, economic, societal and health effects generated in the use of their resources in order to fulfill its functions of teaching, research, outreach and partnership, and stewardship in ways to help society make the transition to a sustainable lifestyle." A review of the declarations revealed that the G8 University Summit Sapporo Sustainability Declaration (No 19, Table A1, Appendix A) held in 2008 in Sapporo, Hokkaido (Japan), specified in the principles that universities should develop sustainable (green) campuses as experimental models $(G 8,2008)$ [27]. The idea was appreciated in almost all subsequent declarations. As a result, universities, including Canadian HEIs, started to appraise the sustainability of their infrastructures in terms of natural resource utilization and associated environmental impacts. In this section, we briefly outline the state of operational-level sustainability assessment in Canadian universities.

The United Nations (in 2030 Agenda for Sustainable Development) released 17 new agenda goals and 169 ambitious targets aimed to engage and define sustainable development. The report called all parties to reduce the accelerating GHG emission and recognized the disappearances among the committed targets and results of holding global temperature below two degree Celsius or 1.5 degree Celsius above pre-industrial levels. The fourth goal proclaims the vital role of education (pedagogical), training and public engagement and access to information are emphasized in this agreement aiming to bridge the technological innovation across the areas of concern, namely energy and medicine [28]. There is an instrumental argument shaped by the notion that HEIs have the ability to shape the future leaders of the world, who morally have an obligation to engage sustainable development in their communities [29].

A university campus consists of different infrastructure systems that consume vast quantities of water and energy throughout their life cycles. Figure 1 shows that most of the energy over the entire lifespan of a building is consumed during the operational phase [30]. During the operational phase, buildings are believed to emit $50 \%$ to $80 \%$ of emissions in their entire lifespan [30-32]. Managing the environmental impacts and optimizing water and energy consumption are critical steps in the pursuit of objectives, such as zero-energy, green buildings, and sustainable campuses [33]. Top 10 GHG emitting HEIs in Canada are listed in Table 1 [34]. The average value for the HEIs listed in Table 1 
is $4.41 \mathrm{tCO}_{2} \mathrm{e}$ per FTE student [34]. In the United States, average annual GHG emissions from all institutional classifications (colleges and universities) were reported as $7.67 \mathrm{tCO}_{2}$ e per FTE student for the year 2010 [35]. With an increase in efforts towards sustainability, significant reductions have been noticed by the HEIs in the country during the present decade. A $13 \%$ reduction in just four years (2010 and 2014) from around $11 \mathrm{tCO}_{2}$ e per FTE student to $9.55 \mathrm{tCO}_{2} \mathrm{e}$ per FTE student was reported by University of Nebraska-Lincoln [36]. Another example is the Massachusetts Institute of Technology where the total net emissions fell $20 \%$ below 2014 baseline, primarily due to shifting to renewable energy sources. It is worth to mention that $3 \%$ increase in total emissions was observed due to an increase in the area of buildings [37]. Hence, continuous efforts would be needed for sustainable buildings' operations in future all over North America.

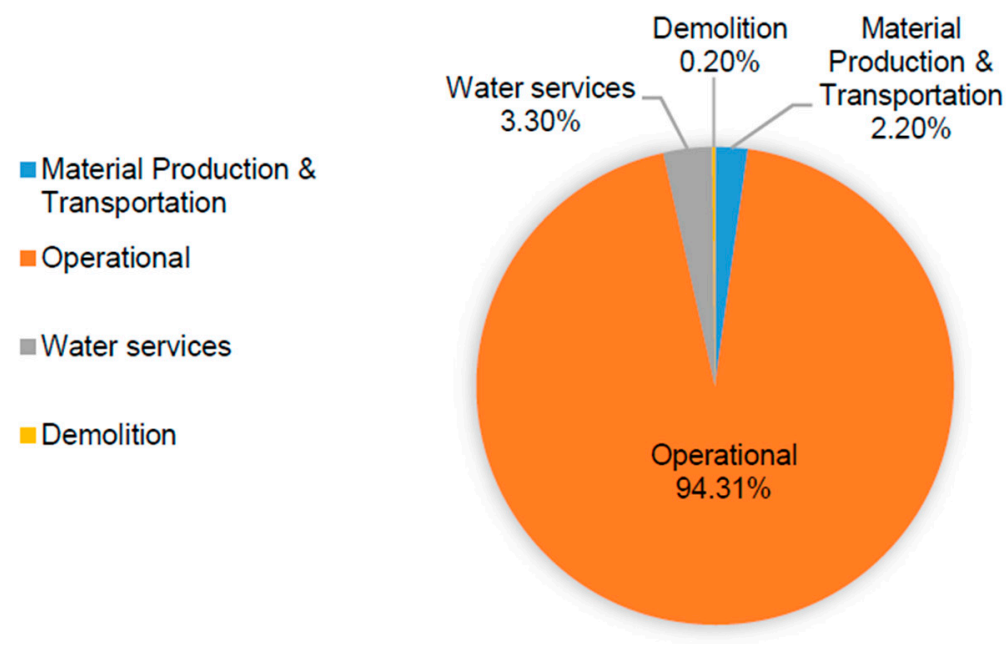

Figure 1. Primary energy usage in buildings.

Table 1. Top 10 Canadian greenhouse gas (GHG) per full-time equivalent students (FTEs) emitting higher education institutions (HEIs) [34].

\begin{tabular}{ccccc}
\hline No & HEI & $\begin{array}{c}\text { Fiscal } \\
\text { Year }\end{array}$ & $\begin{array}{c}\text { Number of } \\
\text { FTEs }\end{array}$ & $\begin{array}{c}\text { GHG Emissions } \\
\text { (tCO } \mathbf{2} \text { e/ FTE) }\end{array}$ \\
\hline 1 & University of Saskatchewan & $2015 / 2016$ & 18,082 & 8.43 \\
2 & University of Alberta & $2015 / 2016$ & 34,693 & 8.24 \\
3 & University of Calgary & $2017 / 2018$ & 28,860 & 6.31 \\
4 & Dalhousie University & $2016 / 2017$ & 17,610 & 4.94 \\
5 & University of New Brunswick & $2015 / 2016$ & 6748 & 4.59 \\
6 & Northern Alberta Institute of Technology & $2013 / 2014$ & 12,479 & 4.34 \\
7 & MacEwan University & $2016 / 2017$ & 12,623 & 2.22 \\
8 & Nova Scotia Community College & $2015 / 2016$ & 10,420 & 1.94 \\
9 & Western University & 2016 & 32,529 & 1.71 \\
10 & McGill University & 2014 & 31,755 & 1.36 \\
\hline
\end{tabular}

HEIs have set targets and goals on individual bases through declarations. These declarations have not been effectively implemented due to lack of incentive structures [2,38-41]. Grindsted [38] studied 31 HEIs declarations and concluded that declarations aid the scope and intensity between HEIs and governments by: setting the role and function of universities (definition of SD in HEIs), declarations have set the base for a broader legislative measure on the national level, and finally increase competition between HEIs which, in turn, led to broader assessment tools. Lozano et al. [39] highlighted the importance of the declarations in three fronts, raise awareness of environmental degradation, communicate progress within universities and their stakeholders, and encourage universities to perform through benchmarking. However, many of these goals have not met their intended targets to date [23]. Studies on the effect of declarations on HEIs' sustainability are ambiguous, it is true that 
declarations played a positive role in setting up a broader definition of sustainable assessment tools in HEIs [29,42]. Although these tools raised the awareness of the sustainability in HEIs, the real outcomes through their practical implementation could not be attained, so far [29,43].

The impacts of buildings in Canadian HEIs have not been clearly identified so far because of the difficulties in setting emission targets for their diverse classification, e.g., residential, administrative, and operational [13]. Buildings have been built or retrofitted at different times using a range of materials and technologies and exhibit varying process efficiency, characteristics, building envelopes, and environmental impacts during their lifetime. Energy and water metabolic flows have significantly increased because of rapid population growth, climate change, enhanced lifestyles, and technological advances. Canada's emission trend report estimated that the per capita emissions during 2011 were around $20 \mathrm{tCO}_{2} \mathrm{e}$ [16]. Diverse trends in HEIs were observed. For instance, the Vancouver campus of the University of British Columbia (UBC) emitted nearly 53,000 $\mathrm{tCO}_{2} \mathrm{e}\left(\sim 1.22 \mathrm{tCO}{ }_{2} \mathrm{e} / \mathrm{FTE}\right)$ [44], and the University of Alberta, operating in extreme cold weather conditions, emitted nearly $300,000 \mathrm{tCO}_{2} \mathrm{e}$ $\left(\sim 8.24 \mathrm{tCO}_{2} \mathrm{e} / \mathrm{FTE}\right)[34]$. Therefore, the type of energy sources and heating and cooling requirements play an important role in the sustainability assessment process.

In Canada, regional goals have been set by local authorities to achieve specific targets for HEIs. For example, based on the 2007 baseline emission levels, UBC set goals for 33\% reduction by 2015, 67\% by 2020 , and $100 \%$ by 2050 [44]. UBC was able to achieve a $28 \%$ reduction in its GHG emission by $2015[45,46]$. These results show the need for more aggressive efforts toward sustainability even in motivated HEIs like the UBC.

\subsection{Sustainability Reporting Systems}

Performance indicators were suggested as a broader tool to assess sustainability performance [47]. Wackernagel and Rees [48] developed an ecological footprint tool to evaluate the performance per unit area of land or number of students. Although the tool lacks standardization and has limited flexibility to include cost-related parameters and insufficient information for decision making [25], it was useful for communicating performance in terms of environmental impact on the basis of unit area or per student [49]. Such a basis provided the opportunity for benchmarking systems with dissimilar sources of water and energy.

HEIs report their SD status for cross comparison with their peers using three prominent systems: the sustainability tracking assessment and rating system (STARS), the campus sustainability assessment framework (CSAF), and the sustainability assessment questionnaire (SAQ). Alghamdi et al. [50] listed 12 assessment tools employed in HEIs based on their relevance, usability, accessibility, and holistic coverage. These tools aim to push the boundaries beyond the conventional declarations listed in Table A1. In addition to STARS and SAQ, they included benchmarking indicators questions (BIQ-AUI), graphic assessment of sustainability in university (GASU), The Green Plan (Green Plan), adaptable model for assessing sustainability in higher education (AMAS), sustainable university model (SUM), green metric (GM), university environmental management system (UEMS), sustainable campus assessment system (SCAS), assessment instrument for sustainability in higher education (AISHE), and unit-based sustainability assessment tool (USAT). These assessment tools are considered to be the most important progress toward the SD of HEIs [51]

STARS is a voluntary and self-reporting system that evaluates the performance of HEIs and ranks them based on five main categories: engagement, planning and administration, academics, innovation, and operations. Each of these categories has subcategories consisting of several indicators. Details on categories, subcategories, indicators, and the assessment procedure are given in Appendix B [9]. Figure 2a-c show sized-based performance results reported by STARS. In Figure 2a, the level of participation is similar across all sizes of HEIs. Figure $2 b$ shows that none of the large-sized HEIs were ranked less than Silver. Conversely, in Figure 2c, $6 \%$ of the small- and medium-sized HEIs obtained a Bronze ranking. We used data from the STARS database to compare the overall sustainability performance scores with the WEC scores. Figure 3 shows that the normalized scores were higher than the individual WEC normalized 
average scores for all sizes of HEIs (i.e., 12 small-sized, 10 medium-sized, and 12 large-sized). None of the HEIs was able to secure the Platinum rating (refer to Appendix B).

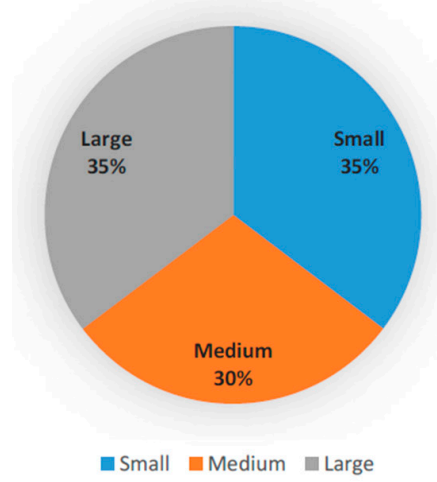

(a)

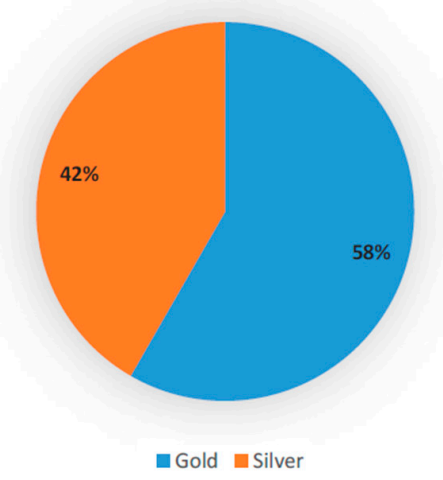

(b)

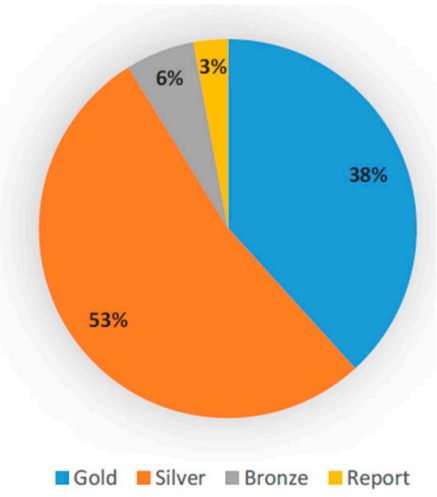

(c)

Figure 2. Summary of the sustainability tracking assessment and rating system (STARS) size-based evaluation: (a) distribution of reporting universities, (b) performance of large-sized universities, (c) performance of small- and medium-sized universities.

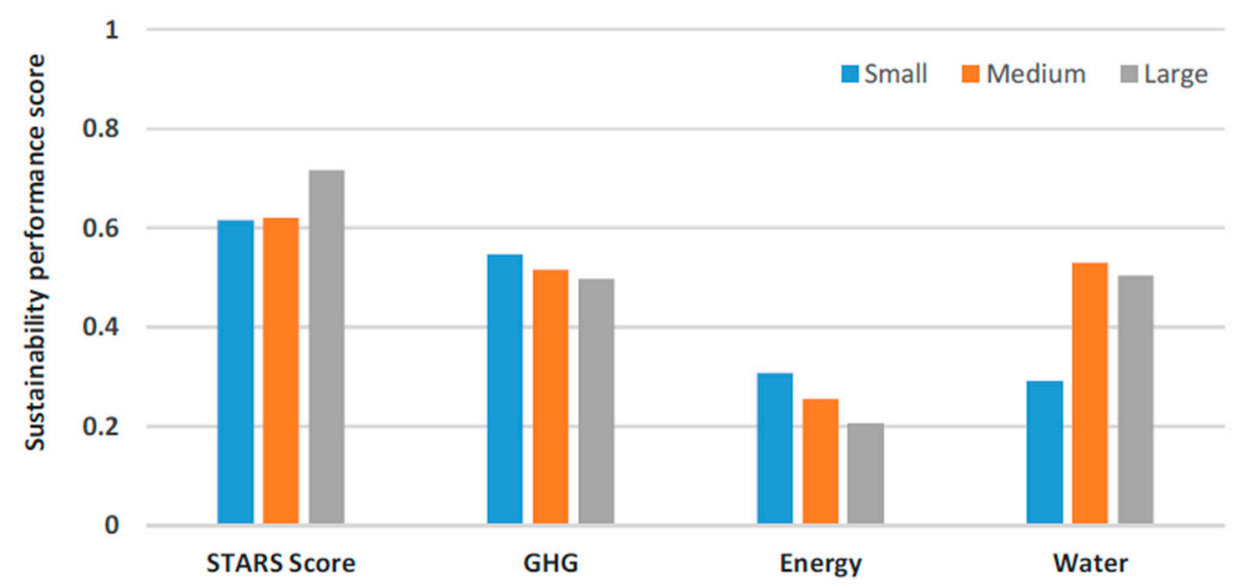

Figure 3. STARS scores vs. water, energy, and carbon (WEC) scores averaged for 12 small-sized, 10 medium-sized, and 12 large-sized HEIs.

Recently, Alghamdi et al. [50] stated: "Although there are many assessment tools and there has been a noticeable progress, this progress is not clearly measurable." Some of the systems require a large amount of data for analyses. For example, Tenley et al. [25] used the CSA framework for sustainability assessment with 175 indicators subgrouped into environmental, social, equity, and economics categories. They stated that different units of indicators also cause difficulties in prioritizing improvement actions.

As mentioned above, STARS uses a more comprehensive approach by covering five performance categories using 73 indicators. In the operations category, 11 indicators (22.7\% of total weight) under five subcategories were related to WEC flows in HEIs, i.e., air and climate: two indicators, buildings: two indicators, energy: two indicators, waste: three indicators, and water: two indicators [9]. Here, indicators under waste were considered to appreciate the ideas of 'waste-to-energy' and 'waste minimization' for SD. Aggregating all the indicators and categorizing the HEIs as Gold, Silver, and Bronze are very useful for overall sustainability ranking.

Alba-Hidalgo et al. [52] made an interesting argument that the most efficient approach to practically implementing the policies towards sustainability is self-assessment while other approaches (participating 
in ranking systems) primarily enhance the competitiveness without confirming whether the improvement actions were actually planned to improve the sustainability at the university or global level or not.

Nevertheless, existing tools with their holistic approach cannot be directly used for sustainability evaluation of engineered systems in HEIs. Hence, technical-level decision making requires: (i) evaluation of WEC flows for engineered systems at the university level for inter-university benchmarking (at regional or national levels) and the setting of future targets for continuous sustainability performance improvement and (ii) classification of HEIs' infrastructure systems, particularly building, based on type and size to evaluate their WEC flows for implementing improvement actions at an intra-university level. The present work addresses the first step toward the sustainability of engineered systems in HEIs.

\section{Methodology}

To pursue SD in HEIs, both the top-down and bottom-up management approaches have been reported in the literature. Lozano [53,54] emphasized the importance of leadership and vision from higher management to the lower hierarchical levels in achieving sustainability targets, e.g., emissions reductions. Others have argued that a bottom-up approach is necessary for raising awareness and addressing the behavioral aspects of resource consumption from the users upwards [23,40,53,55-57]. As experts establish the evaluation criteria of the top-down approach [58], it seems more rational for the technical-level sustainability assessment of HEIs.

The methodology adopted to assess the performance of the WEC flows in this research is shown in Figure 4. Data for WEC flows were obtained from selected universities, government reports, and the STARS database. Based on the available data for a given climatic region, a regression analysis was conducted to interpret the missing data for three unreported universities: Selkirk College (S3), Camosun College (S12), and Concordia University (L3). GHG emissions in HEIs is a function of different factors (utilities) including energy, water consumption, number of FTE students, and floor area, which are measured in different units, and need to be normalized. The utility of overall GHG emissions for all the HEIs was estimated as a function of these different utilities. Normalized sustainability scores for WEC flows using STARS data were also estimated for comparison with the study results. All the HEIs were ranked based on their sustainability performance. Details of the steps of the methodology presented in Figure 4 are described in the following subsections.

\subsection{Size-Based Classification of HEIs}

There is no universally accepted process to classify universities on the basis of the number of FTE students. For example, Wann et al. [59] classified universities as small, medium, and large with numbers of FTE students less than $6589,6590-18,631$, and greater than 18,631 . Herremans and Allwright [60] carried out a survey of North American HEIs and classified them as small with FTEs less than 10,000, medium with FTEs ranging between 10,000 and 20,000, and large with FTEs greater than 20,000. The later classification seems more rational with FTEs in the thousands and is used in the present study whenever reference is made to the size of a university.

Evidently, large-sized HEIs consume more water and energy, and generate higher GHG emissions as compared with small- and medium-sized HEIs. However, they provide larger economies-of-scale than their smaller counterparts when it comes to GHG emissions/number of FTE students. For example, large-sized HEIs can adopt a wide variety of sustainable solutions and technologies that small campuses cannot afford, e.g., biofuel generation as an alternate energy source can generate a huge amount of waste. Small-sized HEIs face challenges such as the affordability of hiring skilled staff, whereas, it is relatively easier to make decisions and implement strategies in smaller organizations [61]. 


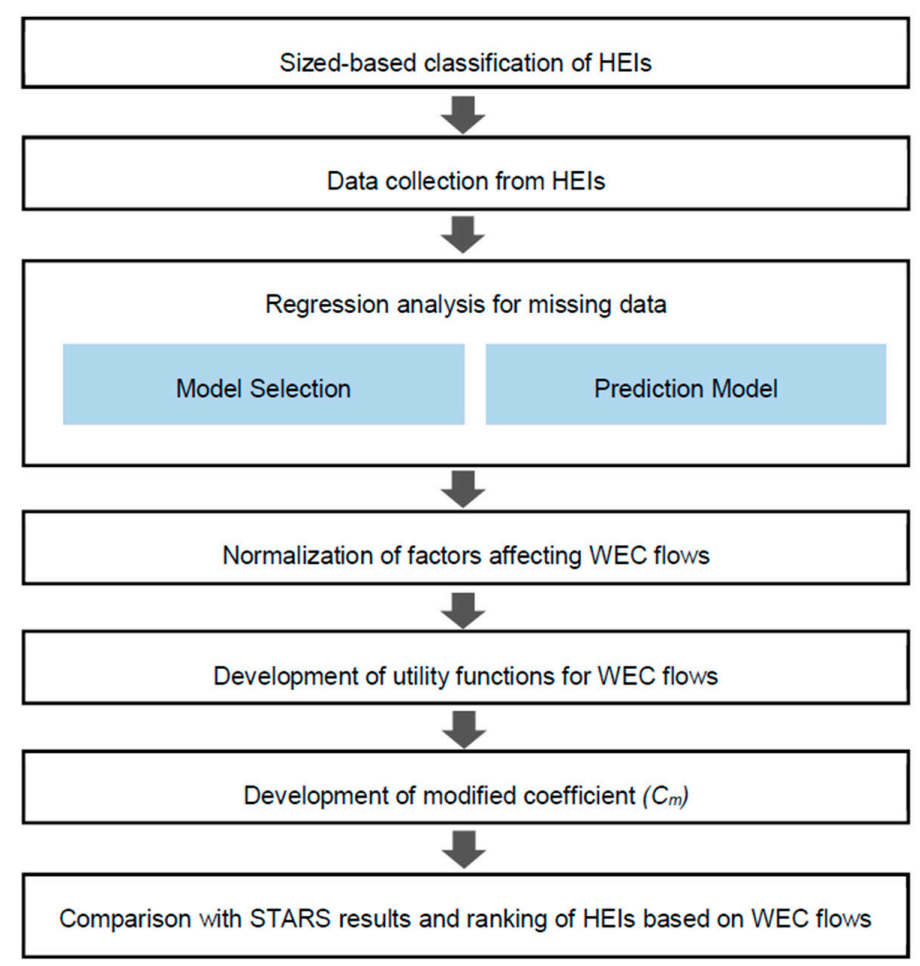

Figure 4. Methodology for inter-university sustainability benchmarking based on WEC flows.

\subsection{Data Collection}

The majority of the data for this study was collected from the STARS self-reporting database. Additional data was obtained from the sustainability reporting cards published by each university and the MOECC's report on the GHG emissions of large facilities in Canada, i.e., GHG scope 1 and 2 [62]. The World Resource Institute/World Business Council for Sustainable Development (WRI/WBCSD) classified GHG emissions into three scope groups. Scope 1 represents direct emissions resulting from onsite or within an organization, e.g., boilers, combustion, and mobile source combustion. Scope 2 consists of indirect sources from outside an organization, e.g., purchased electricity. Scope 3 includes other indirect sources, e.g., employee and student commuting and business travel [35].

Table 2 shows a statistical summary of the data collected. The baseline data collected for this research include climate (temperature), heating degree day (HDD), cooling degree day (CDD), the number of FTE students, building area in $\mathrm{m}^{2}$, GHG emissions in $\mathrm{tCO}_{2} \mathrm{e}$, energy in GJ, and water consumption in gallons $\left(1 \mathrm{~m}^{3}=264.172\right.$ US gallons). A thirty-year average was taken to assess the climate in ${ }^{\circ} \mathrm{C}$. HDD and CDD indicate the cooling and heating requirements of a building. HDD is a measure of the number of degrees and days that the outside air temperature was lower than a specific base temperature that necessitated the operation of the heating system. If the temperature rose above a base temperature, the air conditioning system would start. Many of these parameters are widely used in energy performance assessment and have been extensively covered in the literature [63] in addition to factors like the behavioral aspects of consumption [64].

STARS, a self-reporting system, is a voluntary reporting system in which universities can correct a mistakenly incorrect input value. For example, the Sheridan Institute of Technology reported its mistakes related to GHG emission inventory parameters [65]. There is no provision for penalizing institutions for reporting incorrect data, so some abnormalities in the data have been noticed. For instance, the Dalhousie University reported a value of $84.91 \mathrm{tCO}_{2} \mathrm{e}$ for the indicator of GHG (i.e., OP1 in Appendix B) [66] that was found to be significantly lower than that of all universities, i.e., $39,162 \mathrm{tCO}_{2}$ e. On rechecking this value with the reported field in the university's sustainability report, it was found to be $93,907 \mathrm{tCO}_{2} \mathrm{e}$ [67]. 
Table 2. Summary statistics of data collected.

\begin{tabular}{ccccccccc}
\hline Input & Units & $\mathbf{N}$ & Min & Max & Mean & SD & Q1 & Q3 \\
\hline Climate & ${ }^{\circ} \mathrm{C}$ & 33 & 2.975 & 10.4 & 7.014 & 2.492 & 4.188 & 9.342 \\
HDD & & 33 & 2136 & 11,296 & 4700 & 2179 & 3312 & 5666 \\
CDD & & 33 & 2 & 632 & 260 & 168 & 129.8 & 350.3 \\
FTE & & 33 & 971 & 56,123 & 17,860 & 13,363 & 8224 & 28,413 \\
Area & $\mathrm{m}^{2}$ & 33 & 39,912 & $1,434,513$ & 369,772 & 367,429 & 113,478 & 550,147 \\
GHG & $\mathrm{tCO}_{2} \mathrm{e}$ & 30 & 1021 & 299,127 & 42,953 & 67,409 & 4200 & 52,795 \\
Energy & $\mathrm{GJ}^{1}$ & 33 & 0.0368 & 2.4031 & 0.5815 & 0.6994 & 0.1162 & 0.9647 \\
Water & Gallons $^{1}$ & 31 & $6,326,921$ & $806,266,185$ & $132,466,219$ & $183,924,619$ & $21,774,381$ & $197,980,185$ \\
\hline \multicolumn{7}{c}{ Note: ${ }^{1}\left(1 \mathrm{~m}^{3}=264.172\right.$ US Gallons $)}$.
\end{tabular}

\subsection{Regression Analysis for Missing Data}

When collecting the data, it was observed that the units and scope of the reported data used the same parameter in different reports (i.e., GHG values from different reporting systems were to cover only scopes 1 and 2). For example, the HDD and CDD were not available for some HEIs that participated in the STARS ranking, such as S1, S7, and M6, and these values could not be accessed in local climate databases. To overcome this limitation, the averages of each HEI serving in a given province (climatic region) were used to determine the missing factors (e.g., the average of all HEIs in Ontario was used to find missing information on universities in Ontario). Similarly, other missing factors, e.g., water usage and GHG emissions, were interpolated through as regression analysis.

Chung et al. [64] applied multiple regression analysis to develop a relationship between energy usage intensity (EUI) and various explanatory factors for 30 commercial buildings in Hong Kong. Sun et al. [68] used regression analysis on 95 buildings to benchmark their energy performance. In the past, Birtles and Grigg [69] studied the energy efficiency of buildings and benchmarked them via regression modeling.

In this research, the following linear regression model was developed using the pooled data obtained during data collection to assess unreported or missing data:

$$
M U=a+b_{1} x_{1}+\cdots+b_{n} x_{n}+\varepsilon
$$

where MU is the metabolic usage for GHG (GU), a is the intercept, $b_{1}$ is the coefficient for average climate, $b_{2}$ is the coefficient of HDD, $b_{3}$ is the coefficient of CDD, $b_{4}$ is the coefficient of FTE, $b_{5}$ is the coefficient of floor area of buildings, and $x_{1}$ to $x_{n}$ are the corresponding values for each component of water use. Equation (1) is a function of climate, HDD, CDD, FTE, and building area.

The data summarized in Table 2 does not follow a normal distribution, and a lognormal distribution was applied to all explanatory and response variables. Seven regressions were calculated and the best fit for the models was selected for the GHG function of energy consumption. The reason for the lack of statistical significance of other variables was their high multicollinearity. Energy consumption is highly correlated to the area of buildings, the number of FTE students, HDD, CDD, and water consumption. The results shown in Table 3 represent the best fits of R-squared (R2) coefficients found, i.e., $82.87 \%$ and an adjusted R2 of $82.24 \%$. Similarly, the variance inflation factor and probability were found to be in reasonable ranges.

Table 3. Linear regression coefficients.

\begin{tabular}{ccc}
\hline \multicolumn{3}{c}{ Water Use Coefficients } \\
\hline Intercept & $X_{1}$ & -3.93 \\
Log Energy & $X_{2}$ & 1.0789 \\
\hline
\end{tabular}

For the missing GHG values, a linear model was adjusted through curve fitting between the energy consumption and the amount of GHG emissions used per campus. The values of the two 
missing parameters were calculated using the curve fitting equation shown in Figure 5. For the two non-reported HEIs, i.e., GHG emissions based on the regression model were found to be $10,188.49 \mathrm{tCO}_{2} \mathrm{e}$ for Lakehead University and 22,081.03 $\mathrm{tCO}_{2} \mathrm{e}$ for University of Regina.

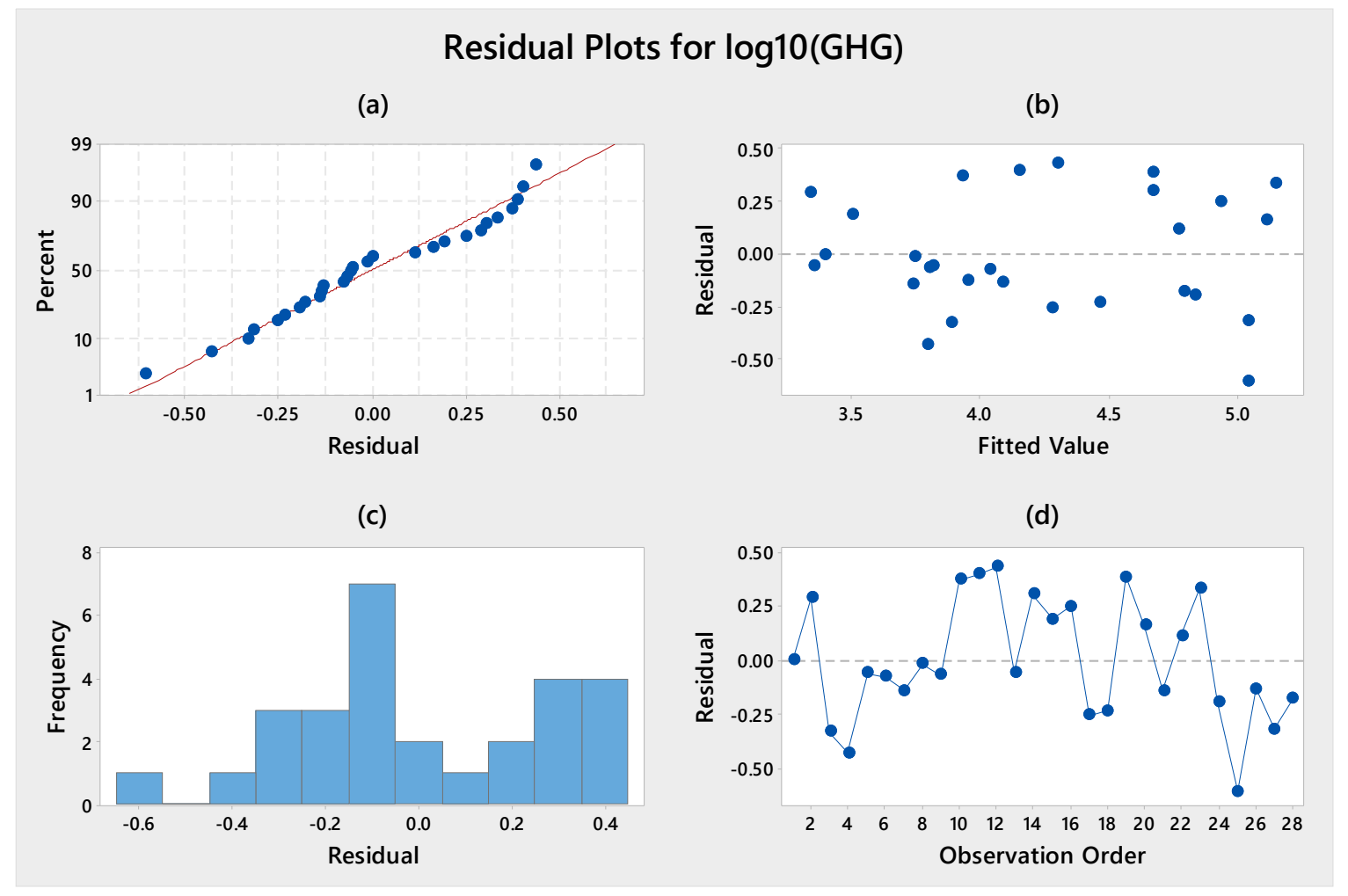

Figure 5. Statistical analysis results for GHG and energy consumption in Canadian HEIs: (a) normal residual probability plot, (b) residual versus fitted value, (c) histogram, and (d) residual versus observation order.

\subsection{Normalization of Factors Affecting WEC Flows}

The main assumption is that GHG emissions are a function of several factors, such as energy, water consumption, number of FTE students, and floor area, and these factors are considered as utilities in the following sections. The inputs are measured in different units, and are replaced with their utilities. Utility is defined as a parameter's energy usage, number of FTE students, floor area, and water consumption. For sustainable operations, these inputs need to be reduced to minimize GHG emissions. In this research, different universities were compared on the basis of the total GHG emitted from these input factors, while the total GHG emissions were assessed in terms of the total utility of a building. Thus, universities are labeled as $U_{i}$, where $i=(1, \ldots N)$, and the total GHG emitted is denoted by $\widetilde{G}[U]_{i}$. The symbols used to define the utilities are derived from the Taylor series variables previously used by Faust and Baranzini [70] for studying the economic performance of 141 water utilities. Van Calker et al. [71] used utility functions to assess the economic, social, and ecological sustainability of dairy farms.

To obtain a rational functional relationship of GHG on such quantities, every quantity needs to be normalized for a rational comparison. The normalized GHG emitted by a university $U_{i}$ as $\widetilde{G}[U]_{i}$ can be defined as follows:

$$
\widetilde{G}[U]_{i}=\frac{G[U]_{i}}{\bar{G}[U]}, \quad \bar{G}[U]=\sum_{i=1}^{N} G[U]_{i}
$$

If $E[U]_{i}=Q[U]_{1 i}$ denotes the total energy consumed, then $[U]_{i}=Q[U]_{2 i}$. The total water consumed, $A[U]_{i}=Q[U]_{3 i}$, corresponds to the total area heated, and $S[U]_{i}=Q[U]_{1 i}$ represents 
the number of occupants in a building. These quantities depend on other factors such as climatic conditions, building envelope, and age of infrastructure. All these factors can be normalized to obtain a rational functional dependence of emitted GHG on these factors as follows:

$$
\begin{gathered}
\widetilde{E}[U]_{i}=\frac{E[U]_{i}}{\bar{E}[U]}, \quad \bar{E}[U]=\sum_{i=1}^{N} E[U]_{i} \\
\widetilde{W}[U]_{i}=\frac{W[U]_{i}}{\bar{W}[U]}, \quad \bar{W}[U]=\sum_{i=1}^{N} W[U]_{i} \\
\widetilde{A}[U]_{i}=\frac{A[U]_{i}}{\bar{A}[U]}, \quad \bar{A}[U]=\sum_{i=1}^{N} A[U]_{i} \\
\widetilde{S}[U]_{i}=\frac{S[U]_{i}}{\bar{S}[U]}, \quad \bar{S}[U]=\sum_{i=1}^{N} S[U]_{i}
\end{gathered}
$$

where, $\widetilde{E}[U]_{i}$ is the normalized energy consumed, $\widetilde{w}[U]_{i}$ is the normalized water consumption, $\widetilde{A}[U]_{i}$ represents the normalized area heated, and the normalized number of people in the building can be defined as $\widetilde{s}[U]_{i}$. The overall GHG emissions can be considered a function of all these different quantities and can be calculated as follows:

$$
\widetilde{G}(U)_{i}=f\left[\widetilde{E}(U)_{i}, \widetilde{W}(U)_{i}, \widetilde{A}(U)_{i}, \widetilde{S}(U)_{i}\right]
$$

In an HEI, the total energy consumed during a year is a function of both the heating and cooling degree days corresponding to the winter and summer seasons. In energy calculations, consideration must be given to both seasons. In this regard, $\widetilde{Q}_{1 i}$ needs to be estimated as the factor obtained from the heating degree day $H D D i$, and $\widetilde{Q}_{2 i}$ as the factor obtained from the cooling degree days $C D D i$. These factors can be defined as follows:

$$
\begin{gathered}
\widetilde{Q}_{1 i}=\frac{H D D i}{\bar{H} D D i}, \bar{H} D D i=\sum_{i=1}^{N} H D D i \\
\widetilde{Q}_{2 i}=\frac{C D D i}{\bar{C} D D i}, \bar{C} D D i=\sum_{i=1}^{N} C D D i
\end{gathered}
$$

These factors are included to normalize the effect of temperature variations because heating and cooling can increase energy consumption in cold and hot climates. High-order corrections are neglected. Only the linear functional dependence of these quantities is considered as a first approximation as follows:

$$
\widetilde{G}(U)_{i}=C_{i}\left[\widetilde{E}(U)_{i}+\widetilde{W}(U)_{i}+\widetilde{A}(U)_{i}+\widetilde{S}(U)_{i}\right]
$$

Equation (6) can also be written as follows:

$$
\widetilde{G}[U]_{i}=C_{i}\left[\widetilde{E}[U]_{i} / \widetilde{Q}_{1 i} \widetilde{Q}_{2 i}|+| \widetilde{W}[U]_{i}|+| \widetilde{A}[U]_{i}|+| \widetilde{S}[U]_{i} \mid\right]
$$

$C_{i}$ is the coefficient used to measure the relative importance of energy when compared with the number of FTE students, floor area, and water usage. For example, water and energy cannot be compared because of the different units used in a single HEI. The comparison of the utility for each factor is more appropriate because all the quantities need to be converted into a consistent unit to incorporate different quantities into the benchmarking process. 


\subsection{Ranking of HEIs Based on WEC Flows}

The coefficients $C_{i}$ with $i=(1, \ldots N)$ measure the relative utility of these quantities (i.e., WEC) as compared with normalized energy consumption. These quantities vary for different regions. For example, it is more difficult to obtain water in the Middle East (i.e., arid environment) compared with Canada, and energy is easy to generate in a region with extensive oil resources. A simple form of the model can be written as follows:

$$
C_{i}=\frac{\widetilde{G}[U]_{i}}{\left|\widetilde{E}[U]_{i}\right|+\left|\widetilde{w}[U]_{\mathrm{i}}\right|+\left|\widetilde{A}[U]_{i}\right|+\widetilde{S}[U]_{i} \mid}=\frac{\widetilde{G}[U]_{i}}{\bar{p}[U] i}
$$

Now, if $C_{1}>C_{2}$ and $\bar{p}[U]_{1}=\bar{p}[U]_{2}$, then $\widetilde{G}[U]_{1}>\widetilde{G}[U]_{2}$, and university $U_{1}$ is producing more GHG emissions for the same average utility as compared with $U_{2}$. This may be attributed to the use of cleaner or less emission-intensive energy sources. As a lower value of $\mathrm{Ci}$ indicates better environmental performance of a university, the final sustainability rank (SR) is calculated as follows:

$$
S R=1-C_{i}
$$

\section{Results}

Based on the relative utility coefficient ' $\mathrm{Ci}$ ', 34 Canadian HEIs were benchmarked (ranked) using the methodology described above. As an example, the reported data of the UBC (Vancouver Campus) is presented in Table 4. The first step normalized all the values by the mean as shown in Equations (2) and (3). The normalized UBC values are listed in Table 4. The new utility (i.e., normalized energy) calculated with Equation (5) was 10.08. The total utility value calculated using Equations (6) and (7) was 22.35. The value of the coefficient calculated by using Equation (8) was 0.0607 . Sustainability ranks were established for all the HEIs using Equation (9). The final sustainability ranks for the 34 HEIs are presented in Figure 6. The figure shows that the sustainability ranks for all the small-sized HEIs and $67 \%$ of the large-sized HEI were higher than the average. While $60 \%$ of the medium-sized HEIs underperformed with sustainability ranks lower than the average.

In Figure 6, the model data were normalized for simplicity with equal values across all the parameters for each HEI assuming they all had equal effects. The variability of the reported data may have an impact on the performance of an HEI. For example, the data was not collected in a cut-off year and the most recent reports were taken into consideration instead. Some of the latest reports published by HEIs were two to five years old. As per the average values of all the reporting HEIs shown in Figure 6, the ten lowest performing HEIs were L4, M3, L6, M4, M2, M7, L7, M5, L2, and M9.

The size-based classification of HEIs better justifies the relationship between the flow of energy and GHG. A strong correlation (i.e., $\mathrm{R}^{2}=0.94$ ) between energy consumed and associated GHG emissions was observed for the small- and medium-sized HEIs in Figure 7. These results are contrary to the combined values of all HEIs, where the R2 value for all the HEIs regardless of size was 0.6442.

Table 4. Data and results of University of British Columbia (UBC, Vancouver).

\begin{tabular}{ccccccccc}
\hline HEI & ${\text { Climate }\left({ }^{\circ} \mathbf{C}\right)}$ & HDD & CDD & FTE & $\begin{array}{c}\text { Area } \\
\left(\mathbf{m}^{\mathbf{2}}\right)\end{array}$ & $\begin{array}{c}\text { GHG } \\
\left(\mathbf{t C O}_{\mathbf{2}} \mathbf{e}\right)\end{array}$ & Energy (GJ) & $\begin{array}{c}\text { Water } \\
\mathbf{( G a l l o n s}^{\mathbf{1}}\end{array}$ \\
\hline UBC (Vancouver) & 10.4 & 5093 & 95.8 & 43,509 & $1,434,513$ & 52,350 & 1.2472 & $806,266,185$ \\
HEI mean & - & 4710 & 262 & 18,157 & 374,902 & 35,453 & 0.5809 & $126,627,438$ \\
Normalized UBC & - & 1.08 & 0.37 & 2.39 & 0.3558 & 1.34 & $3.4711 \times 10^{-6}$ & 6.05 \\
\hline
\end{tabular}

Note: ${ }^{1}\left(1 \mathrm{~m}^{3}=264.172\right.$ US Gallons). 


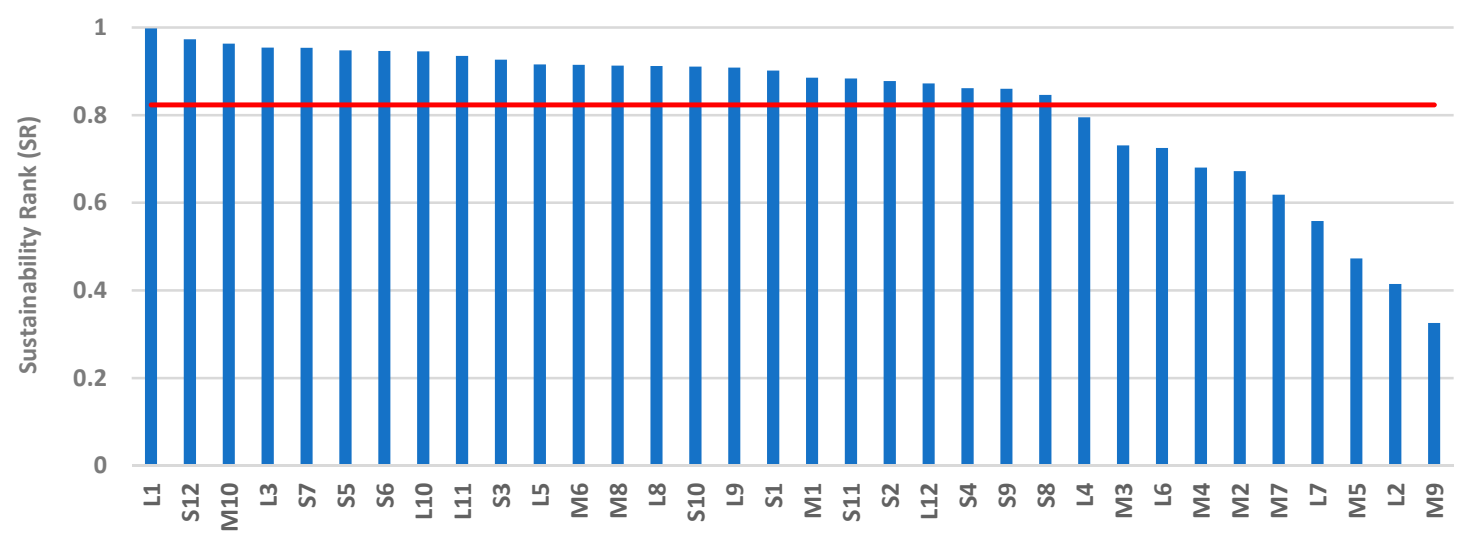

Figure 6. Sustainability ranking of all HEIs in Canada.

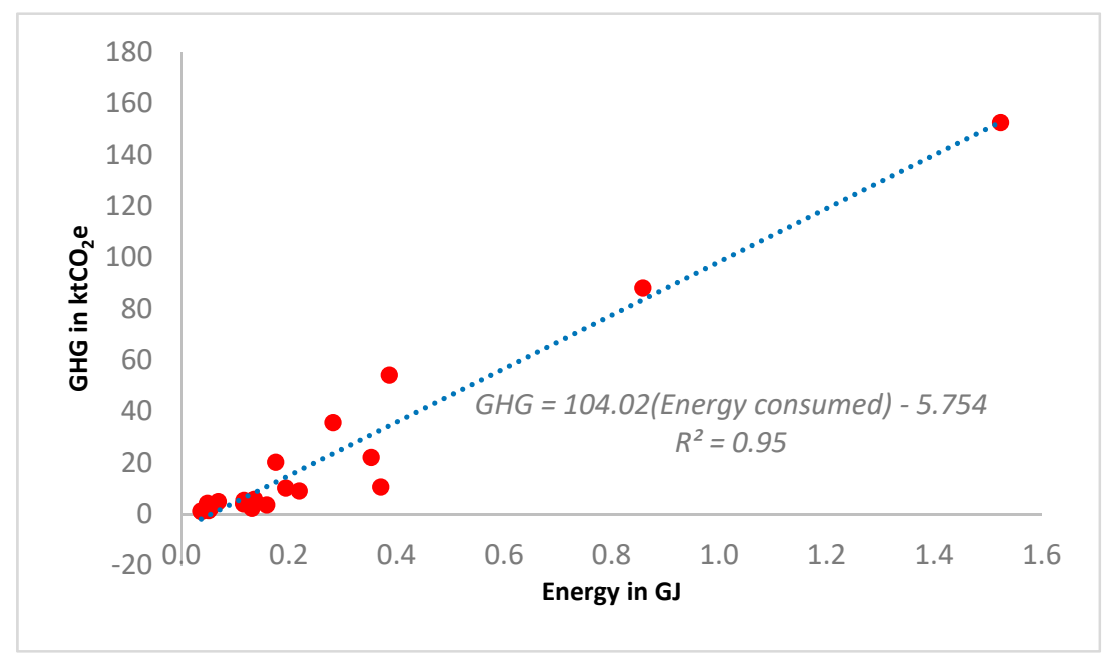

Figure 7. Relationship between energy consumed and GHG emissions for small- and medium-sized HEIs in Canada.

The HEIs with relatively poor performance and their sources of fuels are presented in Table 5. The performance of HEIs in terms of energy conservation varied depending on the mode of energy conservation, efficiency of different processes, and use of GHG intensive fuels, e.g., coal and fossil fuel. For instance, the University of Regina (M3) produced $100 \%$ of its electricity from coal. The Nova Scotia Community College (M2) met 53\% of its electricity requirements from coal, and the MacEwan University (M4) produced $40.6 \%$ of its electricity from coal. Other underperforming HEIs primarily relying on fossil fuels include the University of Calgary (L4), University of Alberta (L7), and University of Saskatchewan (M9). The latest energy report indicates that Alberta's electricity generation is $51 \%$ fueled from coal [72]. However, precise information could not be obtained about these universities' inner-grid combinations (e.g., gas vs. electricity). The province of Saskatchewan generates approximately $34 \%$ of its electricity from coal [73].

The HEIs identified in Table 5 performed poorly because of inefficient energy usage in older buildings (e.g., in terms of building envelope and thermal characteristics). For example, the Nova Scotia Community College (M2) performed better than Dalhousie University (M7) despite both being in the same city and relying on the same electricity grid. The overall performance enhancement in the Nova Scotia Community College was the result of its improved energy efficiency or improved inner-grid distributions (more reliance on renewable energy sources, e.g., hydro or wind).

The data for the 34 HEIs primarily obtained from the STARS database shown in Figure 8a-c presents the aggregated sustainability scores for WEC flows. The values were normalized by dividing the score of each institution in the WEC category by the total grade. Figure 8a illustrates that, regardless 
of size, the performance of all HEIs was similar in terms of GHG emissions while some of the large-sized HEIs clearly underperformed, i.e., L2, L3, L7, and L12. In the case of energy consumption, small-sized HEIs outperformed large- and medium-sized HEIs as shown in Figure $8 \mathrm{~b}$. Figure $8 \mathrm{c}$ shows that the water-consumption performance of medium- and large-sized HEIs was similar.

Table 5. Ten worst-performing HEIs and their fuel sources.

\begin{tabular}{|c|c|c|c|}
\hline No. & HEI & Fuel Source Scope 1 & Fuel Source Scope 2 \\
\hline L4 & University of Calgary & $\begin{array}{l}84 \% \text { natural gas, } 0.22 \% \\
\text { propane }\end{array}$ & $\begin{array}{l}73.8 \% \text { coal, } 20.61 \% \text { natural gas, } 5.39 \% \\
\text { renewables, } 0.18 \% \text { other }\end{array}$ \\
\hline M3 & University of Regina & $100 \%$ natural gas & $100 \%$ coal \\
\hline L6 & Western University & $\begin{array}{l}98 \% \text { natural gas, } 2 \% \\
\text { electricity }\end{array}$ & $\begin{array}{c}40.85 \% \text { hydro, } 55.67 \% \text { nuclear, } 3.49 \% \\
\text { natural gas, biomass, and coal }\end{array}$ \\
\hline M4 & MacEwan University & $100 \%$ natural gas & $\begin{array}{l}3 \% \text { biomass, } 40.65 \% \text { coal, } 6.4 \% \text { hydro, } 41.3 \% \\
\text { natural gas, } 7.9 \% \text { wind, } 0.8 \% \text { other sources }\end{array}$ \\
\hline M2 & $\begin{array}{l}\text { Nova Scotia Community } \\
\text { College }\end{array}$ & $\begin{array}{c}70 \% \text { fuel oil, } 8 \% \text { other } \\
\text { sources, } 22 \% \text { natural gas }\end{array}$ & $\begin{array}{c}2 \% \text { biomass, } 53 \% \text { coal, } 14 \% \text { hydro, } 14 \% \\
\text { natural gas, } 12 \% \text { wind, } 4 \% \text { other sources }\end{array}$ \\
\hline M7 & Dalhousie University & $\begin{array}{c}8 \% \text { biomass, } 84 \% \text { natural } \\
\text { gas, } 3 \% \text { electricity, } 5 \% \\
\text { fuel oil }\end{array}$ & $\begin{array}{l}2 \% \text { biomass, } 63 \% \text { coal, } 7 \% \text { hydro, } 12 \% \\
\text { natural gas, } 9 \% \text { wind, } 7 \% \text { other sources }\end{array}$ \\
\hline L7 & University of Alberta & $\begin{array}{l}54 \% \text { natural gas, } 45.4 \% \\
\text { purchased electricity }\end{array}$ & $\begin{array}{c}53 \% \text { coal, } 38 \% \text { natural gas, } 3 \% \text { hydro, } 1 \% \\
\text { wood biomass, } 5 \% \text { renewables }\end{array}$ \\
\hline M5 & $\begin{array}{l}\text { Northern Alberta } \\
\text { Institute of Technology }\end{array}$ & 1 & 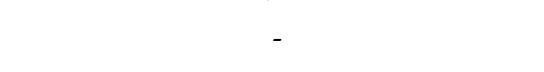 \\
\hline L2 & University of Manitoba & $\begin{array}{l}99.9 \% \text { natural gas, } 0.05 \% \\
\text { fuel oil }\end{array}$ & $95 \%$ hydro, $5 \%$ natural gas \\
\hline M9 & $\begin{array}{l}\text { University of } \\
\text { Saskatchewan }\end{array}$ & $\begin{array}{l}99.96 \% \text { natural gas, } \\
0.04 \% \text { fuel oil }\end{array}$ & $\begin{array}{l}37 \% \text { coal, } 20 \% \text { hydro, } 37 \% \text { natural gas, } \\
0.02 \% \text { solar, } 5 \% \text { wind, } 0.08 \% \text { other sources }\end{array}$ \\
\hline
\end{tabular}

The possible reasons for these results are outlined here. Small universities manage a smaller number of students, have smaller infrastructures, and relatively less-complex processes. The emissions of large-sized HEIs are normalized over a large number of students (i.e., $\mathrm{tCO}_{2} / \mathrm{FTE}$ ) and may result in a higher sustainability ranking. Large universities accommodate more students per water consuming activity, such as laboratories, washrooms, and treatment plants, with larger economies-of-scale. GHG generation per square foot in large-sized HEIs is less than that of medium- and small-size HEIs. Energy consumption is directly related to the size of a building. Therefore, medium-sized HEIs are more critical because buildings are constructed for longer lifecycles.

Regression analysis was performed between the floor area of buildings in the HEIs and their corresponding water consumption, energy consumption, and GHG emissions. The analysis revealed that the 'power function' best fits the relationship between the variables with high $\mathrm{R} 2$ values. Empirical constants for all three relationships are presented in Table 6. The results presented in Table 6 show a strong correlation between the floor area of HEI buildings and WEC flows.

Table 6. Empirical constants for power functions between floor area of HEI buildings and WEC flows.

\begin{tabular}{|c|c|c|c|c|c|c|c|c|}
\hline \multicolumn{9}{|c|}{ Floor Area of Building (thousand $\left.\mathrm{ft}^{2}\right)\left[\mathrm{Y}=\mathrm{a} \mathrm{X}^{\mathrm{b}}\right]$} \\
\hline \multicolumn{3}{|c|}{$\begin{array}{c}X=\text { Water Consumption } \\
\text { (Million Gallons) }^{1}\end{array}$} & \multicolumn{3}{|c|}{$\begin{array}{c}X=\text { Energy Consumption } \\
(G J)\end{array}$} & \multicolumn{3}{|c|}{$\begin{array}{c}\mathrm{X}=\text { GHG Emissions } \\
\text { (Million-ton } \mathrm{CO}_{2} \text { Equivalent) }\end{array}$} \\
\hline a & $\mathrm{b}$ & $R^{2}$ & a & $\mathrm{b}$ & $\mathrm{R}^{2}$ & $\mathrm{a}$ & $\mathrm{b}$ & $R^{2}$ \\
\hline 0.0019 & 1.309 & 0.8790 & 11.908 & 1.273 & 0.942 & 0.2234 & 1.396 & 0.797 \\
\hline
\end{tabular}

A comparison between the STARS ranking and the ranks established in the present study for all sizes of HEIs are presented in Figure 9. The figure shows that of the 10 worst-performing HEIs in Figure 6, the sustainability ranks of four HEIs (M3, M4, M7, and L4) were approximately equal or higher than the STARS ratings. These HEIs need to: (i) implement the SD declarations by embedding sustainability in the fabric of the organizational structure and by planning and setting realistic goals 
and (ii) use renewable fuel sources. The sustainability ranks presented in Figure 9 were calculated based on comparative assessment. Hence, a higher SR does not ensure that there is no need for further improvement. To attain long-term sustainability, HEIs should adopt a continuous performance improvement approach.

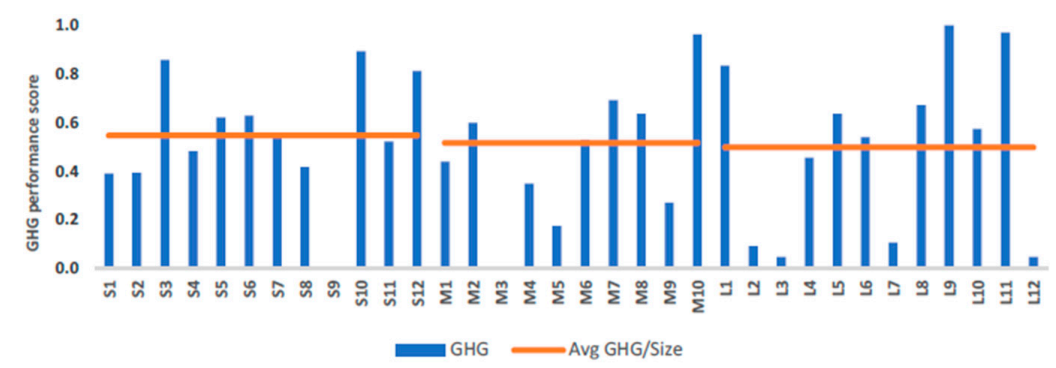

(a)

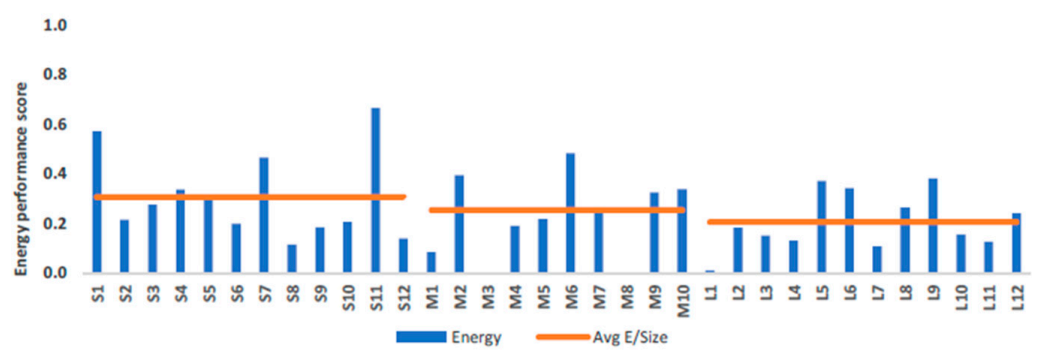

(b)

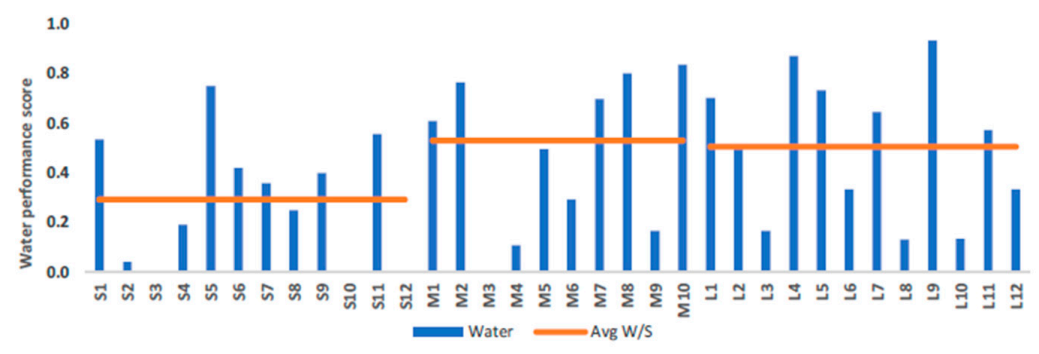

(c)

Figure 8. STARS ranking of Canadian universities by size: (a) GHG emissions performance, (b) energy performance, and (c) water performance.

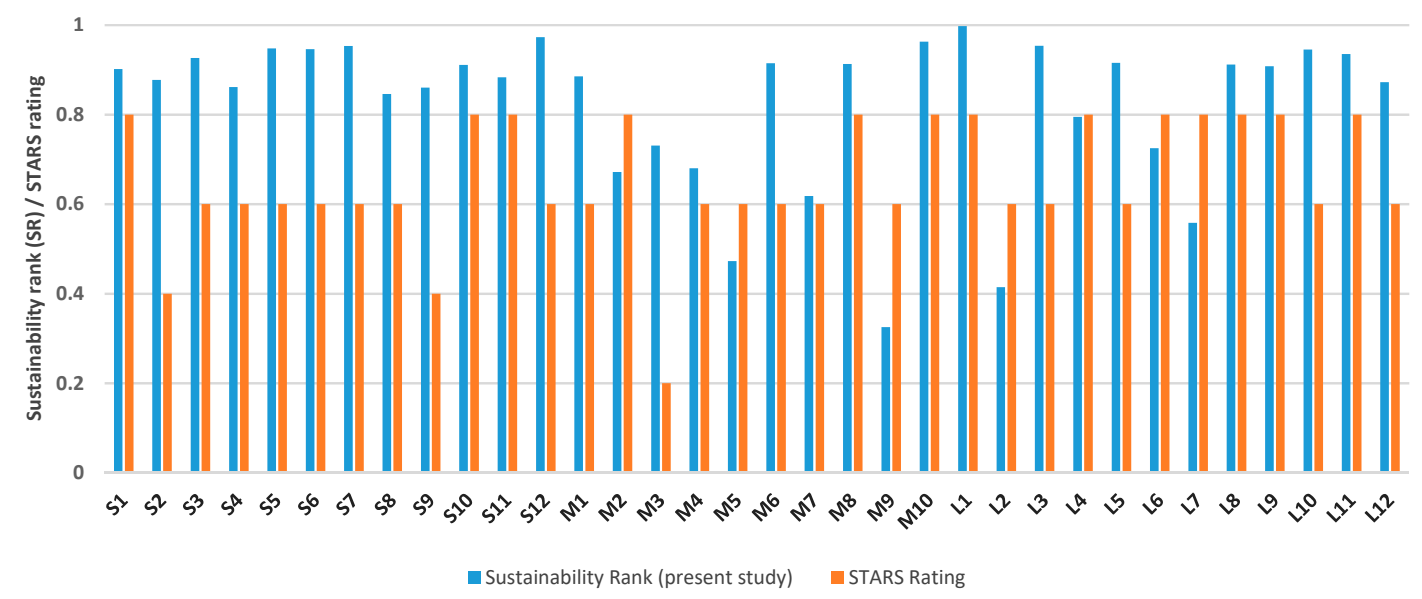

Figure 9. Comparison between STARS overall ranking and SRs based on WEC flows estimated in present study. 


\section{Discussion}

HEIs have sought to implement rating systems for their buildings as an attempt to reduce energy consumption and subsequently reduce GHG emissions. Research has shown that many of these building rating systems could not achieve their desired goals [74,75]. Tilton and ELAsmar [75] compared LEED certified buildings with non-certified buildings based on their functionality (e.g., dormitory, research buildings, and offices) and found that non-certified research buildings consumed less energy than their certified counterparts. According to the results presented in Figure 2, none of the Canadian HEIs attained Platinum rank from STARS (refer to Appendix B for details) and should adopt a continuous performance improvement approach for long-term sustainability.

Leadership in Energy and Environmental Design (LEED) certifies a green building by verifying that the design and construction aimed at improving the sustainability performance, including energy and water efficiency, reduction of carbon emissions, etc. [76]. Agdas et al. [74] studied the EUI of 10 LEED-certified buildings and compared them with non-LEED-certified buildings. It was found that the EUI of LEED-certified buildings was higher than that of the non-LEED-certified buildings. For example, they evaluated 24 campus buildings, 10 of which were LEED-certified and the remaining non-LEED-certified buildings. They could not find a statistically significant difference between both sets of the buildings, in fact, the EUI for the LEED buildings was found to be higher than those of non-certified buildings. Existing systems do not identify the causes of poor performance and the actions required to improve the sustainability performance of universities. This is due to the diverse nature of the parameters being measured (social, environmental, economic) [77]. Moreover, communicating the sustainability assessment of HEIs goals and scope with the stakeholders is not clearly defined [29]. There is a need for an integrated system that can lead HEIs toward continuous improvement in terms of sustainability while maintaining cost effectiveness and simplicity. There is also a need to shift the focus from corrective controls to proactive action [78].

Energy baseline targets (reported values for 2007) were self-imposed by universities in an attempt to conserve or reduce energy consumption. Figure 10 presents a comparison between the performance of HEIs and the baseline energy targets using STARS data. Approximately $58 \%$ of the large-sized universities succeeded in reducing their energy consumption below the baseline, while approximately $70 \%$ of medium-sized and $75 \%$ of small-sized HEIs performed better than the baseline value. The reasons for non-compliance can be unrealistic targeting, an increase in student enrollment, or the absence of any interventions. Overall, approximately $43 \%$ of Canadian HEIs fell behind their baseline values [9]. This is aligned with the data reported from the UK, where educational institutions account for more than $5 \%$ of the non-domestic buildings and are responsible for approximately $14 \%$ of the entire public-sector emissions. Public-funded HEIs had an average EUI of $293 \mathrm{kWh} / \mathrm{m}^{2}$ in FY 2001, which gradually decreased to $287 \mathrm{kWh} / \mathrm{m}^{2}$ by the FY 2006. This EUI level is still substantially below the best practice benchmark of $162 \mathrm{kWh} / \mathrm{m}^{2}$ [79]. The GHG emissions followed similar patterns [80].

HEIs still rely heavily on local electricity providers, which requires that they strive for a net-zero stage. This requires an understanding of the inner components of buildings and how performance can be improved. Imposing taxes on HEIs' intensive fuel usage may result in a positive impact in terms of GHG reduction. To attain high sustainability standards, specific targets are required to be met. The assessment of the state of engineered systems in Canadian HEIs in Figure 10 requires more information for technical-level decision making, e.g., solar coefficient, split of energy used and purchased by sources, age of buildings to determine efficiency, and solar-power street lighting.

Similar to any other built infrastructure, a considerable amount of energy is required in all stages of water and wastewater operations, including water abstraction, water treatment, distribution, wastewater collection, wastewater treatment, and disposal and/or reuse [81]. Energy use can be optimized using efficient water appliances, adopting water conservation strategies, and effective conservation practices. These strategies can be combined with renewable energy use including wastewater energy recovery and onsite solar and wind energy generation for achieving net-zero energy and carbon emissions [82]. 


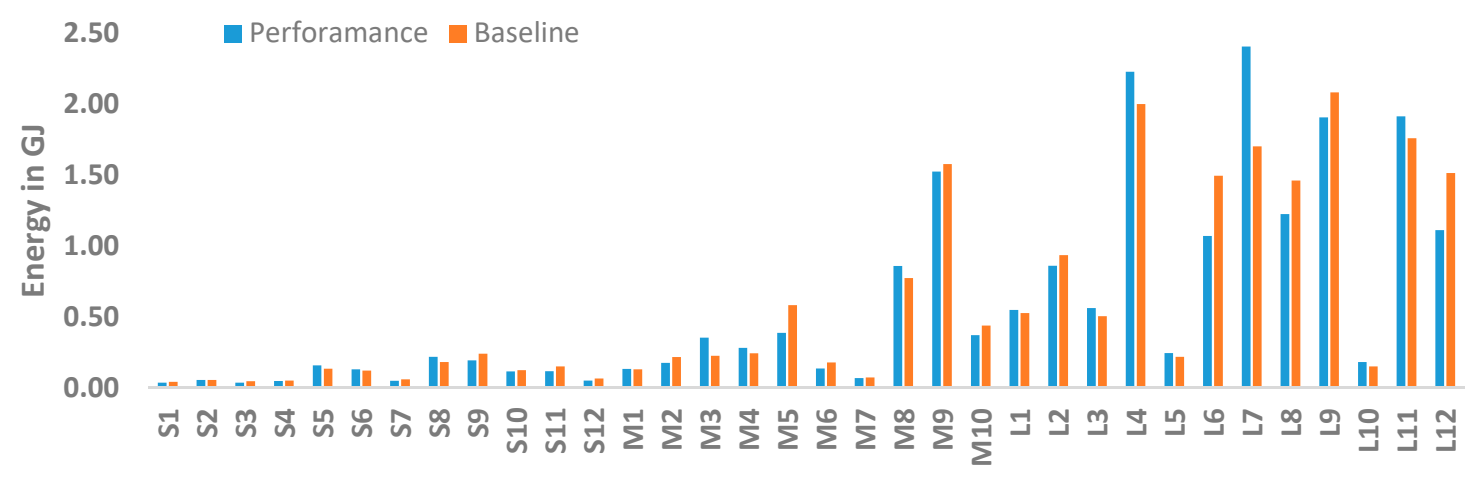

Figure 10. Energy baseline targets and performance of Canadian HEIs based on STARS reporting data.

HEIs require proper planning approaches to reduce both the short-term and long-term environmental impacts during their operations. Comprehensive data are needed for the effective assessment and prudent decision making for selecting rational interventions, i.e., day-to-day maintenance and major long-term improvements. These interventions have their own socioeconomic and environmental implications over the life of a building. An integrated technology-human effort is required for energy and water conservation, GHG emission reductions, and ecosystem protection in a cost-effective manner.

HEIs must address mounting issues owing to an increase in the number of FTE students and associated energy demand, costs associated to increasing fuel prices, aging of buildings and associated reductions in efficiency, uncertainties owing to emerging regulations aimed at curbing carbon emissions, and climate change and its impact on seasonal variations. These factors coupled with the limited available resources to improve these assets will have a significant impact on an institution's ability to forecast future trends, goals, and performance. Therefore, HEIs need to consistently address these changing factors and their impact to attain their sustainability goals.

In 2010, Universitas Indonesia (UI) developed a platform, known as the UI Green Metric World University Ranking [83], for sharing the state of sustainability in HEIs around the globe. The approach of this ranking system consists of six categories, including: (i) setting and infrastructure, (ii) energy and climate change, (iii) waste management, (iv) water usage, (v) transportation, and (vi) environmental education. In addition to improving the overall environmental conditions and promoting sustainability in HEIs, these green campus activities can improve the perception of stakeholders about HEIs and can increase student enrolment.

Continuous performance improvement (CPI) is a top-down management approach intended to manage the quality performance of processes and systems by continuously improving the performance of an organization [84]. CPI aims at reducing wastes, increasing competitiveness, and improving overall performance [85]. The conceptual CPI benchmarking process presented in Figure $11 \mathrm{can}$ be implemented for both inter- and intra-university sustainability assessments. Details of the CPI application in benchmarking processes are provided in Bereskie et al. [86].

A benchmark can be established using a representative sample of similar-sized universities having comparable characteristics, e.g., number of students, and types and age of buildings. The benchmark can be applicable to a specific region to accommodate temporal and geographical factors, such as seasonal and climatic variations and differences in provincial/state regulations. For CPI, future benchmarks can also be established based on improving WEC flow projections from interventions, changing regulations, technological advances, and students' expectations. The goal of the CPI process is not only to improve upon the original benchmark for a factor or group of factors but also to cluster individual HEIs (or buildings in case of inter-university application) closer to the benchmark value.

The resent research provides an insight into the existing state of sustainability in Canadian HEIs. Establishing SRs based on WEC flows will be useful for technical-level decision making. Instead of relying on existing rating systems that cover a wider spectrum of sustainability, technical-level decisions 
can practically improve the existing global and regional GHG scenarios and be a step toward water and energy conservation.

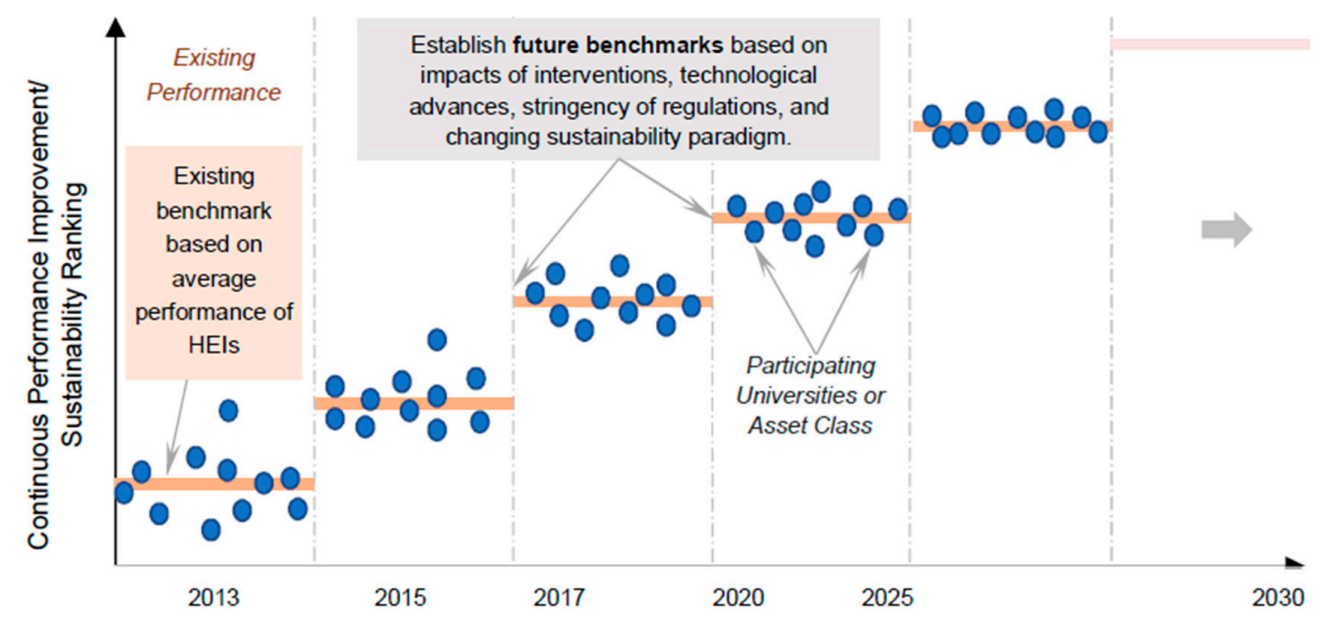

Figure 11. Continuous performance improvement (after Bereskie et al. [86]).

\section{Conclusions}

In Canada, HEIs consume $60 \%$ of the total energy allocated to the educational sector, which is equivalent to approximately 430,000 households. Accordingly, such institutions have been recognized as one of the major contributors to Canada's total GHG emissions. A review of the historical background of declarations revealed that the sustainability of engineered systems (infrastructures) in HEIs was highlighted over the last decade.

Engineered systems in HEIs have been constructed in different eras as a result of increasing enrolments and the establishment of new disciplines. Consequently, they have varying process efficiency, features, and environmental impacts. Existing sustainability ranking systems include a wide range of sustainability indicators and do not measure actual performance in terms of natural-resource consumption and generation of GHG emissions. Technical-level decision makers need to know how the infrastructures, particularly buildings, and processes are utilizing these resources. This can be accomplished by comparing the HEIs based on their energy utilization, water consumption, and production of associated GHG emissions. Instead of relying on existing global sustainability performance, decision makers can select and practically implement actions for long-term sustainability of HEIs, e.g., development of resource conservation strategies and building retrofits.

The inter-university benchmarking methodology developed in this research for sustainability assessment of Canadian HEIs was based on their WEC flows. The methodology incorporates the impact of economies-of-scale by taking the sizes of the HEIs into account for the rational benchmarking of 34 HEIs.

The proposed methodology addresses the difficulties encountered during benchmarking owing to the use of different HEI reporting systems. A regression analysis was used to interpret the missing data for a given climatic region. The GHG emissions of HEIs is a function of different factors (utilities), including energy, water consumption, number of FTE students, and floor area. These factors are measured in different units and were normalized in this research. It is recommended that all universities follow uniform parameters for a rational comparison in the future.

Regression analysis established power function, with strong correlations (i.e., R2 values higher than 0.8 ), between the floor area of buildings in the HEIs and their corresponding water consumption, energy consumption, and GHG emissions.

Canadian HEIs are ranked based on the sustainability performance of their engineered systems while considering the differences in climatic regions, size of campus, number of occupants, and WEC flows. The study results revealed that small-sized HEIs outperformed the large-sized HEIs, whereas, the performance of $60 \%$ of the medium-sized HEIs was found to be less than the average. The reasons 
for such results could be: (i) small HEIs deal with a smaller number of students, smaller infrastructure, and relatively less-complex physical processes, (ii) emissions in large-sized HEIs are normalized over a large number of students (i.e., $\mathrm{tCO}_{2} \mathrm{e} / \mathrm{FTE}$ ), (iii) larger economies-of-scale, i.e., each water consuming facility serves a large number of students in large-sized HEIs, (iv) EUI is less in large-sized HEIs, and (v) energy consumption is directly related to the size of a building, and medium-sized HEIs serving a smaller number of students construct buildings for longer periods of use.

The study results suggest the need for more in-depth investigations to improve the sustainability of different infrastructures' operations through effective operational-level decision making (e.g., efficient retrofits, particularly for older institutions) for all sizes of HEIs. It is expected that future research will focus on the assessment of detailed environmental impacts during the entire life of HEIs, including all construction and operations phases.

Author Contributions: Abdulaziz Alghamdi (A.A.) is the lead author on this publication, having completed the initial writing of the paper, data collection, formal analysis and the methodology. Husnain Haider (H.H.) contributed to conceptualization of the paper, redefining the objectives, narrowing the focus, reviewing the paper and managing the overall research. Kasun Hewage (H.W.) contributed in the literature review and definition of the scope of the work. Rehan Sadiq (R.S.) contributed to the conceptualization of the paper, methodology refinement, and the statistical analysis.

Funding: This research was funded by the Saudi Cultural Bureau in Ottawa for funding this research under the King Abdullah Bin Abdulaziz Scholarship Program.

Acknowledgments: The author gratefully acknowledges the financial support of the Saudi Cultural Bureau in Ottawa for funding this research under the King Abdullah Bin Abdulaziz Scholarship Program. Also, the support of the STARS database and the labs and facilities at the University of British Columbia are highly appreciated. Authors also acknowledge the insights and help of Mir Faizal for his grateful contributions.

Conflicts of Interest: The authors declare no conflict of interest.

\section{Appendix A Historical Background of Declarations on Sustainability of HEIs}

The historical progress of declarations on the sustainability of HEIs is summarized in Table A1. The concept of sustainability of HEIs was first introduced in the Stockholm declaration in 1972 [19]. In 1990, more than 300 universities signed the Talloires declaration with an action plan to introduce sustainability and environmental literacy in HEIs. The UBC signed the Talloires declaration in 1990 and built its first green building in 1996. In 1997, the UBC was ranked first in Canada to adopt an SD policy and opened its sustainability office in 1998. It was also the first to launch the ECOTREK (energy and water intervention program) in Canada and to publish a comprehensive campus-wide strategy in 2006. It has undertaken many initiatives in its pursuit to achieve a sustainable campus [38].

In 1992, the UNCED conference established the correlation between buildings and the capacity for decision making for SD primarily in undeveloped nations [7]. The Earth Charter initiative in 2000 involved discussions between all levels of educational institutions, and not explicitly universities. This charter inspired a new sense of global interdependence by identifying 16 broad-based principles that were later applied to many organizations, cities, NGOs, and the education sector. The aim was to promote interdependence and shared responsibility for the well-being of the whole human family and the greater community of life [79].

In 2012, the Rio+20 declaration was signed by 78 universities, where the overwhelming majority was from Europe. This declaration covered five sustainability aspects including the greening of campuses, teaching SD concepts, supporting sustainability efforts, fostering and engaging in international collaboration, and encouraging research on SD issues [49]. Recently, the UNESCO launched a Global Action Plan in 2014 to generate and scale up actions at all levels and areas of education. This action plan identified five priorities: whole-institution approach, policy support, youth, local communities, and educators. Overall, 272 universities signed the initiative and shared their information to address climate change, $13 \%$ of the participating universities were North American [78]. More than 680 universities around the world have signed the American College and University 
Presidents' Climate Commitment (AUPCC) agreement, which requires participating institutions to reduce GHG emissions [36].

Table A1. Declarations addressing sustainability in HEIs $[2,35,80]$.

\begin{tabular}{|c|c|c|}
\hline No & Year & Declaration \\
\hline 1 & 1972 & Stockholm Declaration on the Human Environment UNEP \\
\hline 2 & 1977 & Tbilisi Declaration UNESCO \\
\hline 3 & 1988 & Manga Charta of European Universities Association (EUA) \\
\hline 4 & 1990 & University Presidents for a Sustainable Future: the Talloires Declaration ULSF \\
\hline 5 & 1991 & Halifax Declaration (International Institute for Sustainable Development) \\
\hline 6 & 1992 & $\begin{array}{c}\text { Agenda } 21 \text { Report of the United Nations Conference on Environment and } \\
\text { Development (UNCED) }\end{array}$ \\
\hline 7 & 1993 & $\begin{array}{c}\text { Ninth International Association of Universities Round Table: the Kyoto } \\
\text { Declaration }\end{array}$ \\
\hline 8 & 1993 & $\begin{array}{l}\text { Association of Commonwealth Universities “Fifteenth Quinquennial } \\
\text { Conference: Swansea Declaration }\end{array}$ \\
\hline 9 & 1994 & CRE Copernicus Charter \\
\hline 10 & 1997 & $\begin{array}{l}\text { International Conference on Environment and Society: Education and Public } \\
\text { Awareness for Sustainability UNESCO }\end{array}$ \\
\hline 11 & 1998 & $\begin{array}{l}\text { World Declaration on Higher Education for the Twenty-first Century: Vision } \\
\text { and action UNESCO }\end{array}$ \\
\hline 12 & 2000 & Earth Charter \\
\hline 13 & 2001 & Luneburg Declaration UNESCO \\
\hline 14 & 2002 & Ubuntu Declaration UN \\
\hline 15 & 2002 & $\begin{array}{c}\text { Johannesburg Plan of Implementation World Summit on Sustainable } \\
\text { Development (WSSD) }\end{array}$ \\
\hline 16 & 2005-2014 & The UN Decade Education for Sustainable Development UNESCO \\
\hline 17 & 2005 & Graz Declaration on Committing Universities to Sustainable Development \\
\hline 18 & 2006 & $\begin{array}{c}\text { Declaration on the Responsibility of Higher Education for a Democratic } \\
\text { Culture Citizenship, Human Rights and Sustainability }\end{array}$ \\
\hline 19 & 2008-2017 & G8 University Summit Sapporo Sustainability Declaration \\
\hline 20 & 2009 & Abuja Declaration on Sustainable Development in Africa \\
\hline 21 & 2009 & Tokyo Declaration of HOPE ASSU \\
\hline 22 & 2009 & $\begin{array}{l}\text { Turin Declaration on Education and Research for Sustainable and } \\
\text { Responsible Development, Italy }\end{array}$ \\
\hline 23 & 2009 & World Conference on Higher Education UNESCO \\
\hline 24 & 2010 & G8 University Summit \\
\hline 25 & 2011 & Copernicus Charta 2.0 \\
\hline 26 & 2012 & Peoples Sustainability Treaty on Higher Education \\
\hline 27 & 2012 & UN Higher Education Sustainability Initiative with Rio+20 \\
\hline 28 & 2015 & $\begin{array}{l}\text { Higher Education Sustainability Initiative: Climate change action for } \\
\text { sustainable development }\end{array}$ \\
\hline
\end{tabular}

\section{Appendix B Assessment Procedure of Sustainability Tracking Assessment and Reporting System (STARS)}

The weights of these subcategories and indicators were assigned based on the recommendations of a panel consisting of members of the STARS's steering committee and staff of the Association for the Advancement of Sustainability in Higher Education (AASHE). The performance points were measured on the overall impact of reporting fields. Owing to the diverse nature of HEIs, STARS insists that 
the credits should be given in a flexible manner because the reporting fields do not apply to all HEIs. The aggregation of these points culminates at an overall rank, such as Platinum, Gold, Silver, or Bronze. An HEI with an overall score of 85 or more obtains a Platinum rating, Gold ranking starts at 65 , Silver at 45 , and the low-performing institutions with a score of 25 or less obtain a Bronze rating. If a university receives a cumulative score lower than 25 , it is shown as incomplete reporting by the HEI. The holistic approach adopted by the STARS ranking in Appendix B may give a higher rank to an HEI that may not be performing the same in terms of its WEC flows.

Table A2. STARS groups/subgroups and points awarded [9].

\begin{tabular}{|c|c|c|c|}
\hline Category/Group & Subgroups & Indicators & Points \\
\hline \multirow{11}{*}{ Academics (AC) } & \multirow{8}{*}{$\begin{array}{l}\text { Curriculum } \\
\text { (40 points) }\end{array}$} & AC1 Academic Courses & 14 \\
\hline & & AC2 Learning Outcomes & 8 \\
\hline & & AC3 Undergraduate Program & 3 \\
\hline & & AC4 Graduate Program & 3 \\
\hline & & AC5 Immersive Experience & 2 \\
\hline & & AC6 Sustainability Literacy Assessment & 4 \\
\hline & & AC7 Incentives for Developing Courses & 2 \\
\hline & & AC8 Campus as a living Laboratory & 4 \\
\hline & \multirow{3}{*}{$\begin{array}{l}\text { Research } \\
\text { (18 points) }\end{array}$} & AC9 Academic Research & 12 \\
\hline & & AC10 Support for Research & 4 \\
\hline & & AC11 Access to Research & 2 \\
\hline \multirow{15}{*}{ Engagement (EN) } & \multirow{9}{*}{$\begin{array}{l}\text { Campus Engagement } \\
\text { (21 points) }\end{array}$} & EN1 Student Educators Program & 4 \\
\hline & & EN2 Student Orientation & 2 \\
\hline & & EN3 Student Life & 2 \\
\hline & & EN4 Outreach Materials and Publications & 2 \\
\hline & & EN5 Outreach Campaign & 4 \\
\hline & & EN6 Assessing Sustainability culture & 1 \\
\hline & & EN7 Employee Educators Program & 3 \\
\hline & & EN8 Employee Orientation & 1 \\
\hline & & EN9 Staff Professional Development & 2 \\
\hline & \multirow{6}{*}{$\begin{array}{l}\text { Public Engagement } \\
\text { (20 points) }\end{array}$} & EN10 Community Partnerships & 3 \\
\hline & & EN11 Inter-Campus Collaboration & 3 \\
\hline & & EN12 Continuing Education & 5 \\
\hline & & EN13 Community Service & 5 \\
\hline & & EN14 Participation in Public Policy & 2 \\
\hline & & EN15 Trademark Licensing & 2 \\
\hline
\end{tabular}


Table A2. Cont.

\begin{tabular}{|c|c|c|c|}
\hline Category/Group & Subgroups & Indicators & Points \\
\hline \multirow{25}{*}{ Operations (OP) } & \multirow{2}{*}{ Air \& Climate (11 points) } & OP1 Greenhouse Gas Emissions & 10 \\
\hline & & OP2 Outdoor Air Quality & 1 \\
\hline & \multirow{2}{*}{ Buildings (8 points) } & OP3 Building Operations and Maintenance & 5 \\
\hline & & OP4 Building Design and Construction & 3 \\
\hline & \multirow{2}{*}{ Energy (10 points) } & OP5 Building Energy Consumption & 6 \\
\hline & & OP6 Clean and Renewable Energy & 4 \\
\hline & \multirow{2}{*}{ Food \& Dining (8 points) } & OP7 Food and Beverage Purchasing & 6 \\
\hline & & OP8 Sustainable Dining & 2 \\
\hline & \multirow{2}{*}{ Grounds (3-4 points) } & OP9 Landscape Management & 2 \\
\hline & & OP10 Biodiversity & $1-2$ \\
\hline & \multirow{4}{*}{ Purchasing (6 points) } & OP11 Sustainable Procurement & 3 \\
\hline & & OP12 Electronics Purchasing & 1 \\
\hline & & OP13 Cleaning and Janitorial Purchasing & 1 \\
\hline & & OP14 Office Paper Purchasing & 1 \\
\hline & \multirow{5}{*}{ Transportation (7 points) } & OP15 Campus Fleet & \\
\hline & & OP16 Student Commute Modal Split & 1 \\
\hline & & OP17 Employee Commute Modal Split & 2 \\
\hline & & OP18 Support for Sustainable & 2 \\
\hline & & Transportation & \\
\hline & \multirow{4}{*}{ Waste (10 points) } & OP19 Waste Minimization and Diversion & \\
\hline & & OP20 Construction and Demolition Waste & 1 \\
\hline & & Diversion & 1 \\
\hline & & OP21 Hazardous Waste Management & \\
\hline & \multirow{2}{*}{ Water (6-8 points) } & OP22 Water Use & $4-6$ \\
\hline & & OP23 Rainwater Management & 2 \\
\hline \multirow{14}{*}{$\begin{array}{c}\text { Planning \& } \\
\text { Administration (PA) }\end{array}$} & \multirow{3}{*}{$\begin{array}{l}\text { Coordination \& Planning } \\
\qquad \text { (8 points })\end{array}$} & PA1 Sustainability Coordination & 1 \\
\hline & & PA2 Sustainability Planning & 4 \\
\hline & & PA3 Participatory Governance & 3 \\
\hline & \multirow{4}{*}{$\begin{array}{l}\text { Diversity \& Affordability } \\
\text { (10 points) }\end{array}$} & PA4 Diversity and Equity Coordination & 2 \\
\hline & & PA5 Assessing Diversity and Equity & 1 \\
\hline & & PA6 Support for Underrepresented Groups & 3 \\
\hline & & PA7 Affordability and Access & 4 \\
\hline & \multirow{3}{*}{$\begin{array}{l}\text { Investment \& Finance } \\
\quad(7 \text { points })\end{array}$} & PA8 Committee on Investor Responsibility & 2 \\
\hline & & PA9 Sustainable Investment & 4 \\
\hline & & PA10 Investment Disclosure & 1 \\
\hline & \multirow{4}{*}{$\begin{array}{l}\text { Well-being \& Work } \\
\text { (7 points) }\end{array}$} & PA11 Employee Compensation & 3 \\
\hline & & PA12 Assessing Employee Satisfaction & 1 \\
\hline & & PA13 Wellness Program & 1 \\
\hline & & PA14 Workplace Health and Safety & 2 \\
\hline \multirow{2}{*}{$\begin{array}{l}\text { Innovation \& } \\
\text { Leadership (IN) }\end{array}$} & \multirow{2}{*}{$\begin{array}{l}\text { (4 bonus points } \\
\text { available) }\end{array}$} & Exemplary Practice (Catalog of credits & \multirow{2}{*}{$\begin{array}{l}0.5 \text { each } \\
1 \text { each }\end{array}$} \\
\hline & & $\begin{array}{c}\text { available) } \\
\text { Innovation (4 credits available) }\end{array}$ & \\
\hline
\end{tabular}

\section{References}

1. World Health Organization (WHO). Health Promoting Universities Concepts, Experience and Framework for Action; Tsouros, A.D., Dowding, G., Thompson, J., Dooris, M., Eds.; World Health Organization: Copenhagen, Denmark, 1998.

2. Caeiro, S.; Filho, W.L.; Jabbour, C.; Azeiteiro, U.M. Sustainability Assessment Tools in Higher Education Institutions; Springer International Publishing: Gewerbestrasse, Switzerland, 2013; p. 432.

3. Cortese, A.D. The Critical Role of Higher Education in Creating a Sustainable Future. Plan. High. Educ. 2003, $13,15-22$. 
4. Orr, D.W. Earth in Mind. In The Heart of Higher Education: A Call to Renewal, 10th ed.; Island Press: San Francisco, CA, USA, 2004.

5. Univcan. Facts and Stats. Available online: http://www.webcitation.org/782U49h9N (accessed on 25 April 2019).

6. Organisation for Economic Co-Operation and Development (OCED). Education at a Glance: OCED Indicators; OCED Publishing: Paris, France, 2014.

7. United Nations (UN). Agenda 21, Ch. 36: Promoting Education and Public Awarness and Training. Available online: http://www.webcitation.org/782UFY9pI (accessed on 24 April 2019).

8. Raj, B. Directed and Systematic Approaches Towards Sustainability in the Twenty-first Century, Chapter in The Mind of an Engineer. In The Mind of an Engineer; Ghosh, P., Raj, B., Eds.; Springer: Singapore, 2016.

9. AASHE. Technical Manual Version 2.1. Available online: http://www.webcitation.org/782VI1ulG (accessed on 4 October 2017).

10. Bauer, M.; Bormann, I.; Kummer, B.; Niedlich, S.; Rieckmann, M. Sustainability Governance at Universities: Using a Governance Equalizer as a Research Heuristic. High. Educ. Policy 2018, 31, 491-511. [CrossRef]

11. Alshuwaikhat, H.M.; Abubakar, I. An integrated approach to achieving campus sustainability: Assessment of the current campus environmental management practices. J. Clean. Prod. 2008, 16, 1777-1785. [CrossRef]

12. NSF. What's an Engineered System? Available online: erc-assoc.org/content/what $\% \mathrm{E} 2 \% 80 \% 99$ s-engineeredsystem (accessed on 28 November 2018).

13. Ward, I.; Ogbonna, A.; Altan, H. Sector review of UK higher education energy consumption. Energy Policy 2008, 36, 2939-2949. [CrossRef]

14. Geng, Y.; Liu, K.; Zue, B.; Fujita, T. Creating a "green university" in China: A case of Shenyang university. J. Clean. Prod. 2013, 61, 13-19. [CrossRef]

15. Larsen, H.N.; Pettersen, J.; Solli, C.; Hertwich, E.G. Investigating the Carbon Footprint of a University-The case of NTNU. J. Clean. Prod. 2013, 48, 39-47. [CrossRef]

16. Canada's Emission Trends. Environment Canada. 2013. Available online: https://www.ec.gc.ca/ges-ghg/ 985F05FB-4744-4269-8C1A-D443F8A86814/1001Canada\T1\textquoterights\%20Emissions\%20Trends\% 202013_e.pdf (accessed on 20 April 2015).

17. NRC. Energy Efficiency Trends in Canada 1990-2013. Available online: https://www.nrcan.gc.ca/sites/www. nrcan.gc.ca/files/energy/pdf/trends2013.pdf (accessed on 7 June 2015).

18. NRC. Consumption of Energy Survey for Universities, Colleges and Hospitals 2003. 2004. Available online: http://oee.nrcan.gc.ca/corporate/statistics/neud/dpa/data_e/consumption03/universities.cfm?attr=0 (accessed on 24 April 2017).

19. NRC. Comprehensive Energy Use Database. Available online: https:/oee.nrcan.gc.ca/corporate/statistics/ neud/dpa/showTable.cfm?type $=C P \&$ sector $=$ com\&juris $=$ ca\&rn $=3 \&$ page $=0$ (accessed on 8 December 2017).

20. United Nations (UN). Stockholm Declaration on the Human Environment; United Nations: Stockholm, Sweden, 1972; Volume 1650, p. 383.

21. Dlouhá, J.; Barton, A.; Janoušková, S.; Dlouhý, J. Social learning indicators in sustainability-oriented regional learning networks. J. Clean. Prod. 2013, 49, 64-73. [CrossRef]

22. Klein-Banai, C.; Theis, T.L. Quantitative analysis of factors affecting greenhouse gas emissions at institutions of higher education. J. Clean. Prod. 2013, 48, 29-38. [CrossRef]

23. Anand, C.K.; Bisaillon, V.; Webster, A.; Amor, B. Integration of sustainable development in higher education-A regional initiative in Quebec (Canada). J. Clean. Prod. 2015, 108, 916-923. [CrossRef]

24. Lozano, F.J.; Lozano, R. Developing the curriculum for a new Bachelor's degree in Engineering for Sustainable Development. J. Clean. Prod. 2014, 64, 136-146. [CrossRef]

25. Tenley, M.C.; Chelsea, D.; Jennifer, L.; Laura, B. Developing ecological footprint scenarios on university campuses: A case study of the University of Toronto at Mississauga. Int. J. Sustain. High. Educ. 2008, 9, 4-20. [CrossRef]

26. Velazquez, L.; Munguia, N.; Platt, A.; Taddei, J. Sustainable university: What can be the matter? J. Clean. Prod. 2006, 14, 810-819. [CrossRef]

27. Komiyama, H. G8 University Summit: Sapporo Sustainability Declaration (SSD). Available online: https: //www.global.hokudai.ac.jp/wp-content/uploads/2017/05/SSD.pdf (accessed on 25 April 2019). 
28. United Nations (UN). Transforming Our World: The 2030 Agenda for Sustainable Development. Available online: https:/sustainabledevelopment.un.org/content/documents/21252030\%20Agenda\%20for\% 20Sustainable\%20Development\%20web.pdf (accessed on 26 April 2019).

29. Fischer, D.; Jenssen, S.; Tappeser, V. Getting an empirical hold of the sustainable university: A comparative analysis of evaluation frameworks across 12 contemporary sustainability assessment tools. Assess. Eval. High. Educ. 2015, 40, 785-800. [CrossRef]

30. Scheuer, C.; Keoleian, G.A.; Reppe, P. Life cycle energy and environmental performance of a new university building: Modeling challenges and design implications. Energy Build. 2003, 35, 1049-1064. [CrossRef]

31. Junnila, S.; Horvath, A.; Guggemos, A. Life-Cycle Assessment of Office Buildings in Europe and the United States. J. Infrastruct. Syst. 2006, 12, 10-17. [CrossRef]

32. Collinge, W.; Landis, A.; Jones, A.; Schaefer, L.; Bilec, M. Dynamic life cycle assessment: Framework and application to an institutional building. Int. J. Life Cycle Assess. 2013, 18, 538-552. [CrossRef]

33. Omer, A.M. Energy, environment and sustainable development. Renew. Sustain. Energy Rev. 2008, 12, 2265-2300. [CrossRef]

34. AASHE. The Sustainability Tracking, Assessment \& Rating System. Available online: https://reports.aashe. org/institutions/participants-and-reports/ (accessed on 27 April 2019).

35. Sinha, P.; Schew, W.A.; Sawant, A.; Kolwaite, K.J.; Strode, S.A. Greenhouse Gas Emissions from U.S. Institutions of Higher Education. J. Air Waste Manag. Assoc. 2010, 60, 568-573. [CrossRef] [PubMed]

36. University of Nebraska-Lincoln (UNL). Greenhouse Gas Emissions. Available online: https://sustainability. unl.edu/greenhouse-gas-emissions (accessed on 27 April 2019).

37. Massachusetts Institute of Technology (MIT). Climate Action Plan Update 2018: Reducing MIT's Emissions. Available online: http://sustainability.mit.edu/sites/default/files/resources/2018-11/2018_ghg_summary_ report_handout.pdf (accessed on 21 April 2019).

38. Grindsted, T.S. Sustainable universities-From declarations on sustainability in higher education to national law. Environ. Econ. 2011, 2, 29-36. [CrossRef]

39. Lozano, R.; Lukman, R.; Lozano, F.J.; Huisingh, D.; Lambrechts, W. Declarations for sustainability in higher education: Becoming better leaders, through addressing the university system. J. Clean. Prod. 2013, 48, 10-19. [CrossRef]

40. Wright, T. The Evolution of Sustainability Declarations in Higher Education. In Higher Education and the Challenge of Sustainability: Problematics, Promise, and Practice; Corcoran, P.B., Wals, A.E.J., Eds.; Springer: Dordrecht, The Netherlands, 2004; pp. 7-19.

41. Wright, T.S.A. Definitions and frameworks for environmental sustainability in higher education. Int. J. Sustain. High. Educ. 2002, 3, 203-220. [CrossRef]

42. Findler, F.; Schönherr, N.; Lozano, R.; Stacherl, B. Assessing the Impacts of Higher Education Institutions on Sustainable Development-An Analysis of Tools and Indicators. Sustainability 2018, 11, 59. [CrossRef]

43. Clarkson, R.E.; Samson, K.; Bekessy, S.A. The failure of non-binding declarations to achieve university sustainability: A need for accountability. Int. J. Sustain. High. Educ. 2007, 8, 301-316. [CrossRef]

44. UBC. Annual Sustainability Report 2013-2014. Available online: https://sustain.ubc.ca/sites/sustain.ubc. ca/files/uploads/CampusSustainability/CS_PDFs/PlansReports/Reports/2013-2014-Annual-SustainabilityReport.pdf (accessed on 10 September 2016).

45. UBC. UBC Vancouver Campus-2007 GHG Emissions Inventory. Available online: https: //sustain.ubc.ca/sites/sustain.ubc.ca/files/uploads/CampusSustainability/CS_PDFs/ClimateEnergy/ UBCGHGInventory_2007.pdf (accessed on 10 September 2016).

46. UBC. UBC Vancouver Campus-2015 Greenhouse Gas Emissions Inventory. Available online: https: //sustain.ubc.ca/sites/sustain.ubc.ca/files/UBCGHGInventory_2015.pdf (accessed on 10 September 2016).

47. Martin, S.; Jucker, R. Educating Earth-literate Leaders. J. Geogr. High. Educ. 2005, 29, 19-29. [CrossRef]

48. Rees, W.; Wackernagel, M. Urban ecological footprints: Why cities cannot be sustainable-And why they are a key to sustainability. Environ. Impact Assess. Rev. 1996, 16, 223-248. [CrossRef]

49. Kate, F. Institutional ecological footprint analysis-A case study of the University of Newcastle, Australia. Int. J. Sustain. High. Educ. 2001, 2, 48-62. [CrossRef]

50. Alghamdi, N.; den Heijer, A.; de Jonge, H. Assessment tools' indicators for sustainability in universities: An analytical overview. Int. J. Sustain. High. Educ. 2017, 18, 84-115. [CrossRef] 
51. Shriberg, M. Institutional assessment tools for sustainability in higher education: Strengths, weaknesses, and implications for practice and theory. Int. J. Sustain. High. Educ. 2002, 3, 254-270. [CrossRef]

52. Alba-Hidalgo, D.; Benayas del Álamo, J.; Gutiérrez-Pérez, J. Towards a Definition of Environmental Sustainability Evaluation in Higher Education. High. Educ. Policy 2018, 31, 447-470. [CrossRef]

53. Lozano, R. Incorporation and institutionalization of SD into universities: Breaking through barriers to change. J. Clean. Prod. 2006, 14, 787-796. [CrossRef]

54. Lozano, R. A tool for a Graphical Assessment of Sustainability in Universities (GASU). J. Clean. Prod. 2006, 14, 963-972. [CrossRef]

55. Lozano García, F.J.; Kevany, K.; Huisingh, D. Sustainability in higher education: What is happening? J. Clean. Prod. 2006, 14, 757-760. [CrossRef]

56. Disterheft, A.; Ferreira da Silva Caeiro, S.S.; Ramos, M.R.; de Miranda Azeiteiro, U.M. Environmental Management Systems (EMS) implementation processes and practices in European higher education institutions-Top-down versus participatory approaches. J. Clean. Prod. 2012, 31, 80-90. [CrossRef]

57. Yuan, X.; Zuo, J.; Huisingh, D. Green Universities in China-What matters? J. Clean. Prod. 2013, 61, 36-45. [CrossRef]

58. Haider, H.; Sadiq, R.; Tesfamariam, S. Intra-utility performance management model (In-UPM) for the sustainability of small to medium sized water utilities: Conceptualization to development. J. Clean. Prod. 2016, 133, 777-794. [CrossRef]

59. Wann, D.L.; Schrader, M.P.; Allison, J.A.; McGeorge, K.K. The Inequitable Newpaper Ceverage of Men's and Womens Athletics at Small, Medium, and Large Universities. J. Sport Soc. Issues 1998, 22, 79-87. [CrossRef]

60. Herremans, I.; Allwright, D.E. Research: Environmental Management Systems at North American Universities: What Drives Good Performance? ULSF: Washington, DC, USA, 2000.

61. Haider, H.; Sadiq, R.; Tesfamariam, S. Selecting performance indicators for small and medium sized water utilities: Multi-criteria analysis using ELECTRE method. Urban Water J. 2014. [CrossRef]

62. ECCC. Greenhouse Gas Emissions from Large Facilities Canada. 2014. Available online: https://www.canada. ca/en/environment-climate-change/services/environmental-indicators.html (accessed on 15 February 2018).

63. Piper, J.E. Operations and Maintenance Manual for Energy Management; Routledge: Abingdon, UK, 1998.

64. Chung, W.; Hui, Y.V.; Lam, Y.M. Benchmarking the energy efficiency of commercial buildings. Appl. Energy 2006, 83, 1-14. [CrossRef]

65. AASHE. Dalhousie Univeristy Greenhouse Gas Emissions. Available online: https://stars.aashe.org/ institutions/dalhousie-university-ns/report/2015-01-07/OP/air-climate/OP-1/ (accessed on 4 November 2017).

66. AASHE. Sheridan Institute of Technology and Advanced Learning OP-1: Greenhouse Gas Emissions. Available online: https://stars.aashe.org/institutions/sheridan-institute-of-technology-and-advancedlearning-on/report/2015-04-20/OP/air-climate/OP-1/ (accessed on 4 November 2017).

67. Dalhousie_University. Greenhouse Gas (GAS) Inventory Report 2014-2015. Available online: https://www.dal.ca/content/dam/dalhousie/pdf/dept/sustainability/Dalhousie\%20GHG\%20Inventory\% 202014-15\%20Final.pdf (accessed on 4 November 2017).

68. Sun, H.; Lee, S.E.; Priyadarsini, R.M.T.; Wu, X.; Chia, Y.; Majid, S. Building energy performance benchmaking and simulation under tropical climatic conditions. In Proceedings of the International Workshop on Energy Perofrmance and Environmental Quality of Buildings, Milos Island, Greece, 6-7 July 2006.

69. Birtles, A.B.; Grigg, P. Energy efficiency of buildings: Simple appraisal method. Build. Serv. Eng. Res. Technol. 1997, 18, 109-114. [CrossRef]

70. Faust, A.-K.; Baranzini, A. The economic performance of Swiss drinking water utilities. J. Product. Anal. 2014, 41, 383-397. [CrossRef]

71. van Calker, K.J.; Berentsen, P.B.M.; Romero, C.; Giesen, G.W.J.; Huirne, R.B.M. Development and application of a multi-attribute sustainability function for Dutch dairy farming systems. Ecol. Econ. 2006, 57, 640-658. [CrossRef]

72. Alberta, E. Alberta's Electricity Generation. 2015. Available online: http://www.energy.alberta.ca/Electricity/ 682.asp (accessed on 4 October 2017).

73. SaskPower. A Powerful Connection. Available online: http://www.saskpower.com/wp-content/uploads/ 2015-16_SaskPower_annual_report.pdf (accessed on 4 October 2017).

74. Agdas, D.; Srinivasan, R.S.; Frost, K.; Masters, F.J. Energy use assessment of educational buildings: Toward a campus-wide sustainable energy policy. Sustain. Cities Soc. 2015, 17, 15-21. [CrossRef] 
75. Tilton, C.; El Asmar, M. Assessing LEED versus Non-LEED Energy Consumption for a University Campus in North America: A Preliminary Study. In Proceedings of the ICSI 2014, Long Beach, CA, USA, 6-8 November 2014; pp. 1071-1076.

76. BU. What Is LEED. Available online: http://www.bu.edu/sustainability/what-were-doing/green-buildings/ leed/\%3E\%20cited\%20on\%20November\%202018 (accessed on 20 November 2018).

77. Waheed, B.; Khan, F.I.; Veitch, B. Developing a quantitative tool for sustainability assessment of HEIs. Int. J. Sustain. High. Educ. 2011, 12, 355-368. [CrossRef]

78. Boons, F.A.A.; Baas, L.W. Types of industrial ecology: The problem of coordination. J. Clean. Prod. 1997, 5, 79-86. [CrossRef]

79. HEEPI. Results of the HEEPI HE Building Energy Benchmarking Initative. 2004. Available online: http://heepi.org.uk/ (accessed on 8 December 2015).

80. Altan, H. Energy efficiency interventions in UK higher education institutions. Energy Policy 2010, 38, 7722-7731. [CrossRef]

81. Tuladhar, A.; Cheng, P.; Xiao, C.; Siemens, E. An Investigation into the Potential for PVC Reduction in Building Floorings. Available online: https://open.library.ubc.ca/collections/18861/items/1.0108802 (accessed on 20 April 2019).

82. Novotny, V. Water and energy link in the cities of the future-Achieving net zero carbon and pollution emissions footprint. Water Sci. Technol. 2011, 63, 184-190. [CrossRef]

83. Tiyarattanachai, R.; Hollmann, N.M. Green campus initiative and its impacts on quality of life of stakeholders in green and non-green campus universities. SpringerPlus 2016, 5, 84. [CrossRef] [PubMed]

84. Bhuiyan, N.; Baghel, A. An overview of continuous improvement: From the past to the present. Manag. Decis. 2005, 43, 761-771. [CrossRef]

85. Elmuti, D.; Kathawala, Y. An overview of benchmarking process: A tool for continuous improvement and competitive advantage. Benchmark. Qual. Manag. Technol. 1997, 4, 229-243. [CrossRef]

86. Bereskie, T.; Haider, H.; Rodriguez, M.J.; Sadiq, R. Framework for continuous performance improvement in small drinking water systems. Sci. Total Environ. 2017, 574, 1405-1414. [CrossRef]

(C) 2019 by the authors. Licensee MDPI, Basel, Switzerland. This article is an open access article distributed under the terms and conditions of the Creative Commons Attribution (CC BY) license (http://creativecommons.org/licenses/by/4.0/). 